\title{
Water Sorption Behaviors of Novel Biohybrid Hydrogels as Effective Sorbents in Water-Solvent Binary Mixtures
}

\author{
Erdener Karadağ $\breve{~}^{*}$, Belgin Yel, Semiha Kundakcı, Ömer Barış Üzüm \\ Aydın Adnan Menderes University, Fen-Edebiyat Faculty, Chemistry Department, Aydın, Turkey \\ Email: *ekaradag@adu.edu.tr
}

How to cite this paper: Karadağ, E., Yel, B., Kundakc1, S. and Üzüm, Ö.B. (2020) Water Sorption Behaviors of Novel Biohybrid Hydrogels as Effective Sorbents in Water-Solvent Binary Mixtures. Journal of Encapsulation and Adsorption Sciences, 10, 43-70.

https://doi.org/10.4236/jeas.2020.103003

Received: August 12, 2020

Accepted: September 19, 2020

Published: September 22, 2020

Copyright $\odot 2020$ by author(s) and Scientific Research Publishing Inc. This work is licensed under the Creative Commons Attribution International License (CC BY 4.0).

http://creativecommons.org/licenses/by/4.0/

\begin{abstract}
Novel sorbent hydrogels containing acrylamide/sodium vinylsulfonate, carboxymethyl cellulose and zeolite were synthesized with free radical solution polymerization by using ammonium persulfate/ $N, N, N$, $N$ 's-tetramethylethylenediamine as redox initiating pair in presence of poly(ethylene glycol) diacrylate as crosslinker. It was to investigate the water uptake properties of series of the novel hydrogels, the semi IPNs and the hybrid/biohybrid composite hydrogel sorbents synthesized in this study. Water uptake studies were performed in water and in water-solvent (acetone, methanol and tetrahydrofuran) binary mixtures at $25^{\circ} \mathrm{C}$, gravimetrically. Some swelling and diffusion parameters were calculated and discussed. It has been seen that the lower equilibrium swelling factor values in all solvent compositions in comparison with the equilibrium swelling factor values in water.
\end{abstract}

\section{Keywords}

Acrylamide/Sodium Vinylsulfonate, Biohybrid Hydrogel, Swelling, Carboxymethyl Cellulose, Zeolite, Water-Solvent Binary Mixtures

\section{Introduction}

Highly swollen crosslinked hydrophilic copolymers called "hydrogels" are synthesized by free radical crosslinking copolymerization with some multifunctional crosslinkers with some co-monomers including hydrophilic groups for increasing of their swelling capacity. Water uptake property of hydrogels or "hungry networks" accounts for a great number of biomedical and technological applications. Highly swollen polymeric gel with the ability to absorb water in high amounts is again under investigation, because of their potential applications in 
bioengineering, biomedicine, and other related areas [1] [2] [3]. Hydrogels are three-dimensional networks of hydrophilic polymer chains with properties in between liquids and solids. One of the most interesting features is their capability to swell as well as to shrink depending on their surroundings. A hydrogel can be defined as a polymeric material that exhibits the ability to swell in water and retain a significant fraction of water within its structure without dissolving [4] [5] [6].

Gels do not dissolve but swell/shrink (i.e., change their volume) in contact with liquid phases. Due to characteristic properties such as swell ability in water, hydrophilicity, biocompatibility, and lack of toxicity, hydrogels have been utilized in a wide range of bioengineering, biomedicine, and food industry [7] [8] [9]. Novel functional materials such as composite polymers are new materials which have produced properties wanted through the development of specialized areas. Advanced novel polymers have promising potentials for development and application in this area, because of a variety of some physicochemical properties (form, size, size distribution, porosity, etc.) that can be tailored and possibility of their modification by inserting various functional groups, their sensitivity to change of the external stimuli and general reversibility of adsorption process, enabled by easy and complete regeneration without significant decrease in adsorption capacities [1] [2] [3]. Polymer/clay or polymer/zeolite hybrid composite polymeric systems have received great attention because of their relatively low production cost and high adsorption capacity for water, some dyes and metal. Swelling or water sorption property of hydrogels accounts for a great number of biomedical and technological applications [1] [4] [9] [10].

Novel hydrogels have the ability to sense and response to environmental stimuli, such as changes of $\mathrm{pH}$, temperature, or the concentration of some model-biochemical and/or industrial species and then release their load as a result of such a change [11] [12] [13]. One of the advantages of hydrogels consists in their capability of high swelling and in exhibiting a first-order phase transition (collapse) caused by a small change in external conditions such as temperature, electric field, solvent composition, etc. [14]-[19]. Hydrogels that are responsive to specific molecules, such as some physiological fluids or biochemical species can be used as biosensors as well as in drug delivery systems and in aqueous solvent mixtures [11] [12] [13] [14] [15]. These hydrogels can be used as controlled-release delivery devices for bio-active agents and agrochemicals. Hydrogels are usually sensitive to the solvent medium composition. When a water-miscible non-solvent is added to water, the water-swollen hydrogel often shrinks or collapses. Depending on the gel chemical structure, the solvent nature and water-solvent composition, the gel shrinkage may be gradual (continuous) or abrupt (discontinuous) [14]-[19].

The present paper deals with a preliminary report about swelling properties of a series of a novel hybrid/biohybrid composite hydrogel sorbent systems containing polysaccharide/zeolite (ZEO) polyelectrolyte based on acrylamide (AAm)/ sodium vinylsulfonate (SVS) and carboxymethyl cellulose (CMC), and a mineral 
structure such as ZEO. In our previous paper, it has been reported swelling and dye sorption characterization of AAm/SVS/CMC/ZEO hybrid/biohybrid hydrogels [20]. Here, AAm is a highly hydrophilic monomer and SVS is an anionic monomer, $\mathrm{CMC}$ is a natural polymer and $\mathrm{ZEO}$ is a mineral structure by composed of hydrated alumino silicates, $\mathrm{SiO}_{4}$ and $\mathrm{AlO}_{4}$. In this respect, a series of copolymeric hydrogels were synthesized by changing the content of SVS, CMC and ZEO. CMC is anionic carboxymethyl ether of cellulose with tasteless, non-toxic and water-soluble characteristics. Zeolites are a large group of crystalline, hydrated alumino silicates, characterized by three-dimensional structure with pores which can accommodate water molecules, different cations, positively charged atomic groups and even smaller organic molecules [20]. In this present research, it was of interest to examine the swelling characterization and behavior of AAm based including of SVS, CMC and ZEO hybrid/biohybrid hydrogels in water and water-solvent binary mixtures of water and organic solvents (i.e., acetone, methanol and tetrahydrofuran) mixtures of various compositions.

\section{Materials and Methods}

\subsection{Raw Materials}

Acrylamide (AAm), the initiator-ammonium persulfate (APS), the activator $N, N, N$, $N$ '-tetramethylethylenediamine (TEMED) and zeolite (ZEO) were supplied by Sigma, Steinheim, Germany. Anionic co-monomer such as sodium vinylsulfonate (vinylsulfonic acid, sodium salt-tech. $25 \mathrm{wt} \%$ solution in water) (SVS) and a multifunctional crosslinker such as poly (ethylene glycol) diacrylate (PEGDA, $M_{n}=700$ ) as a crosslinker were supplied from Aldrich, Steinheim, Germany. Sodium carboxymethyl cellulose (CMC) was purchased from Fluka, Steinheim, Germany [20]. The solvents that were used in swelling studies, acetone (ACE), methanol (MET) and tetrahydrofuran (THF) were supplied by Riedel de Haën, Germany. All chemicals were used as received.

\subsection{Hydrogel Sorbent Synthesis}

The hydrogels, the semi-interpenetrating polymer networks, and the hybrid/biohybrid composite hydrogel systems developed in this study were prepared by free radical crosslinking copolymerization of AAm monomer with addition of SVS and a multifunctional crosslinker such as PEGDA as a crosslinker [20]. Highly swollen AAm/SVS hydrogels, AAm/SVS/CMC semi IPNs, AAm/SVS/ZEO hybrid hydrogels, and AAm/SVS/CMC/ZEO biohybrid hydrogels were prepared by free radical crosslinking copolymerization of AAm monomer with addition of an anionic comonomer such as SVS and a multifunctional crosslinker such as PEGDA. The modes of purification and specifications of the sources of water, the monomers AAm and SVS, crosslinker; PEGDA, initiator; APS and activator; TEMED were given in our related study [20].

In our previous study, water sorption and dye uptake properties of highly swollen AAm/SVS hydrogels, AAm/SVS/CMC semi IPNs, AAm/SVS/ZEO hy- 
brid hydrogels, and AAm/SVS/CMC/ZEO biohybrid hydrogels have been reported [20]. But, it would be better than, if some details of the synthesis of the hydrogel systems can be given, again. To prepare highly swollen and chemically crosslinked AAm hydrogel systems, AAm weighing $1.0 \mathrm{~g} / 14.07 \mathrm{mmol}$ was dissolved in $1.0 \mathrm{~mL}$ water. Then, $60 \mu \mathrm{L}(0.544 \mathrm{mmol})$ of SVS was added to aqueous other AAm solution (for AAm/SVS hydrogels containing $60 \mu \mathrm{L}$ of SVS) at room temperature, $\left(25^{\circ} \mathrm{C}\right)$. Then, $120 \mu \mathrm{L}(1.088 \mathrm{mmol}), 180 \mu \mathrm{L}(1.633 \mathrm{mmol}), 240 \mu \mathrm{L}$ $(2.176 \mathrm{mmol})$, and $300 \mu \mathrm{L}(2.72 \mathrm{mmol})$ of SVS were added to other aqueous AAm solutions, respectively for containing different amount of SVS in AAm/SVS hydrogel systems. After these additions, for the synthesis, $0.25 \mathrm{~mL} / 0.004 \mathrm{mmol}$ of $1 \%$ concentration of PEGDA and $0.2 \mathrm{~mL} / 0.044 \mathrm{mmol}$ aqueous solutions of APS (5.0 g APS/100 mL water) and $0.25 \mathrm{~mL} / 0.017 \mathrm{mmol} 1 \%$ concentration of TEMED were added these aqueous solutions (Table 1) [20].

In preparation, the solutions were placed in special cylindrical plastic molds (having $7.0 \mathrm{~mm}$ of diameter and $3.0 \mathrm{~mm}$ of height) (Figure 1), then, they waited for an hour for gelation. After gelation, the samples were washed with distilled water by several times. Then, they were dried in air and vacuum, and stored for swelling studies [20].

For the synthesis of AAm/SVS/CMC semi IPNs, AAm/SVS/ZEO hybrid

Table 1. Compositions of the hydrogel systems containing AAm, SVS, ZEO and CMC.

\begin{tabular}{|c|c|c|c|c|}
\hline Abbreviation & $\begin{array}{l}\text { SVS } \\
(\mu \mathrm{L})\end{array}$ & $\begin{array}{l}\text { Water } \\
(\mathrm{mL})\end{array}$ & $\begin{array}{c}\text { ZEO }(\mathrm{mL}) \\
(2.0 \% \mathrm{ZEO} / \text { water } \\
\text { suspension system })\end{array}$ & $\begin{array}{c}\text { CMC }(\mathrm{mL}) \\
(2.0 \% \text { aqueous } \\
\text { CMC solution })\end{array}$ \\
\hline AAm/SVS & $0-300$ & 1.0 & - & - \\
\hline AAm/SVS/ZEO & $0-300$ & 0.50 & 0.50 & - \\
\hline AAm/SVS/CMC & $0-300$ & 0.50 & - & 0.50 \\
\hline AAm/SVS/ZEO/CMC & $0-300$ & - & 0.50 & 0.50 \\
\hline $\begin{array}{c}\text { AAm/SVS/ZEO } \\
\text { (for ZEO changing) }\end{array}$ & 240 & $\begin{array}{c}0.75-0.50- \\
0.25-0.00\end{array}$ & $\begin{array}{c}0.25-0.50- \\
0.75-1.00\end{array}$ & - \\
\hline $\begin{array}{c}\text { AAm/SVS/CMC } \\
\text { (for CMC changing) }\end{array}$ & 240 & $\begin{array}{c}0.75-0.50- \\
0.25-0.00\end{array}$ & - & $\begin{array}{c}0.25-0.50- \\
0.75-1.00\end{array}$ \\
\hline
\end{tabular}

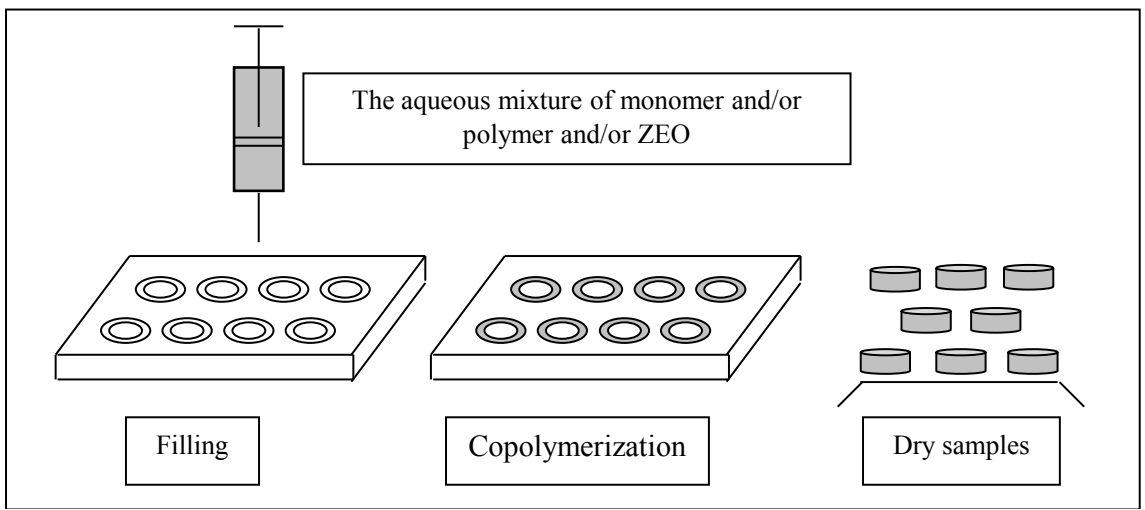

Figure 1. Schematic representation of the preparation of the hydrogel systems. 
hydrogels and AAm/SVS/CMC/ZEO biohybrid hydrogels, the modes of specifications of the sources of water, the monomers AAm and SVS, ZEO, polysaccharide; CMC, crosslinker; PEGDA, initiator; APS and activator; TEMED were given in our related study [20]. For synthesis of all used samples in this study, the quantities of AAm, SVS, CMC and ZEO were presented in Table 1. Schematic representation of preparation of AAm/SVS hydrogels, AAm/SVS/CMC semi IPNs, AAm/SVS/ZEO hybrid hydrogels, and AAm/SVS/CMC/ZEO biohybrid hydrogels have been presented in Figure 1.

\subsection{Swelling Studies}

The dried hydrogels were immersed in water, in pure solvents such as ACE, MET and THF, and water-solvent (ACE, MET and THF) binary mixtures of various compositions. The gravimetric method was employed to study the swelling characterization. Swollen gels were removed from water, pure solvents and binary mixtures of water-60\% of solvent (ACE, MET and THF) at predetermined times, blotted dry, and weighed in air. Water, pure solvents and water-solvent binary mixtures were kept at $25^{\circ} \mathrm{C} \pm 0.1^{\circ} \mathrm{C}$ to allow the hydrogels to reach equilibrium for examines of solvent composition effect on swelling properties of the hydrogel systems [5].

In the next swelling tests, for the investigation of the effect of composition of solvent on swelling, highly swollen AAm/SVS hydrogels, AAm/SVS/CMC semi IPNs, AAm/SVS/ZEO hybrid hydrogels, and AAm/SVS/CMC/ZEO biohybrid hydrogels containing $240 \mu \mathrm{L}$ SVS have been swollen at water and binary mixtures of various compositions such as water-20\%; $40 \% ; 60 \%$ and $80 \%$ of solvent (ACE, MET and THF). From these measurements, some swelling and diffusion parameters have been determined [5].

\section{Results and Discussion}

Novel AAm/SVS hydrogels, AAm/SVS/CMC semi IPNs, AAm/SVS/ZEO hybrid hydrogels, and AAm/SVS/CMC/ZEO biohybrid hydrogels were prepared by free radical solution polymerization [20]. For the synthesis of AAm/SVS/CMC semi IPNs, AAm/SVS/ZEO hybrid hydrogels and AAm/SVS/CMC/ZEO biohybrid hydrogels, the modes of specifications of the sources of water, the monomers AAm and SVS, zeolite (ZEO), polysaccharide; sodium carboxymethyl cellulose (CMC), crosslinker; PEGDA, initiator; ammonium peroxydisulfate/ammonium persulfate (APS) and activator; $N, N, N, N$-tetramethylethylenediamine (TEMED) were given in our related study [20]. In this related study, chemical structures of monomers and the probable binding and crosslinking mechanism have been presented for AAm/SVS copolymer or hydrogel systems [20]. Highly swollen AAm based hydrogels made by the polymerization of AAm with an anionic monomer such as SVS, and/or ZEO and/or polysaccharide; such as CMC were investigated as a function of composition to find materials with swelling in binary mixtures of various compositions of water-solvent (ACE, MET and THF). 
Chemical structures of monomers and the probable binding and crosslinking mechanism of AAm/SVS copolymers have been presented in Figure 2. The dried hydrogels are glassy and very hard, but swollen gels are soft. The hydrogel systems via radical chain polymerization are a well-established procedure. Upon swelling the hydrogels were strong enough to retain their shape. There have been presented the digital camera images of AAm/SVS hydrogels and AAm/SVS/CMC semi IPN hydrogels as dry state or swollen state in water (Figure 3) and as dry state or swollen state in binary mixtures of water- $60 \%$ of THF as representative (Figure 4). The capacity of swelling of the hydrogels can be seen from Figure 3 and Figure 4 as visual.

\subsection{Swelling Performance}

The water, some solvents such as ACE, MET and THF, or some liquids such as water/solvent binary mixtures intake of initially dry hydrogels was followed for novel AAm/SVS hydrogels, AAm/SVS/CMC semi IPNs, AAm/SVS/ZEO hybrid hydrogels, and AAm/SVS/CMC/ZEO biohybrid hydrogels. The hydrogels were waited in water, in solvents and in binary mixtures of various compositions of water-solvent (ACE, MET and THF). Here it was seen that there is no swelling in $100 \%$ composition of the solvents such as ACE, MET and THF [5].

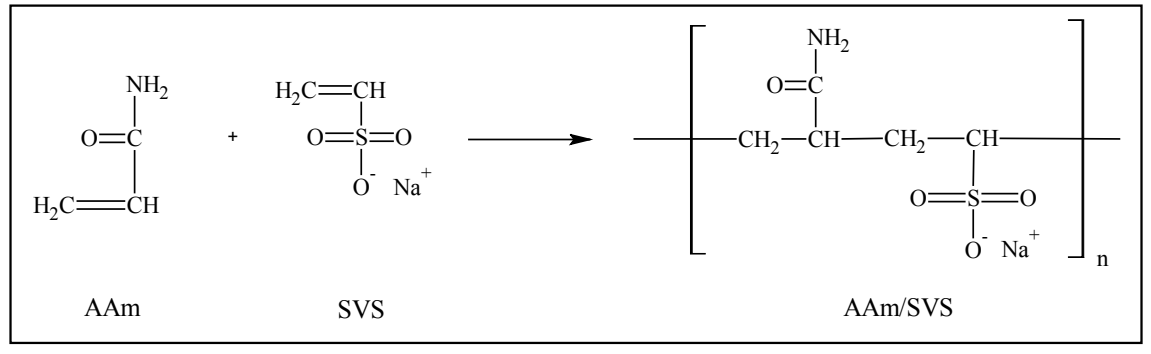

Figure 2. Chemical structures of monomers and the probable binding and crosslinking mechanism of AAm/SVS copolymers.
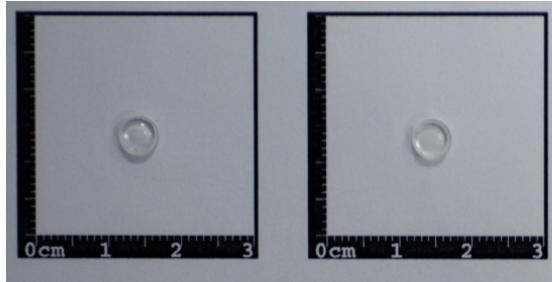

o SVS

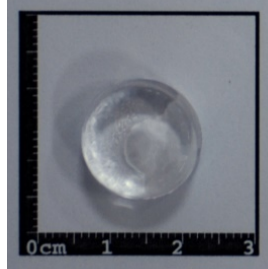

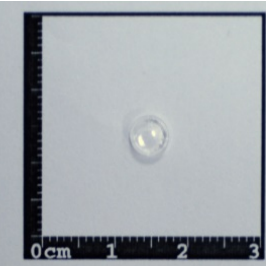

$0 \mathrm{SVS} / \mathrm{CMC}$
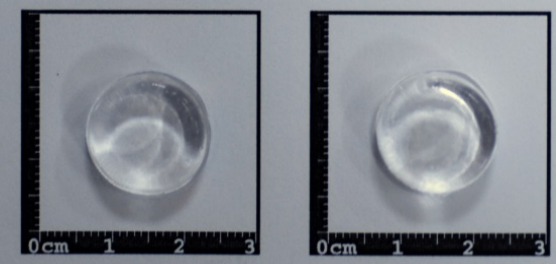

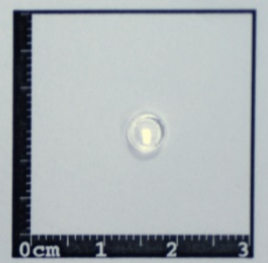

240 SVS/CMC

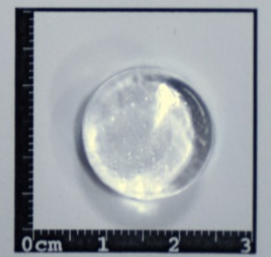

Figure 3. The digital camera images of AAm/SVS hydrogels and AAm/SVS/CMC semi IPN hydrogels (as dry state or swollen state in water). 


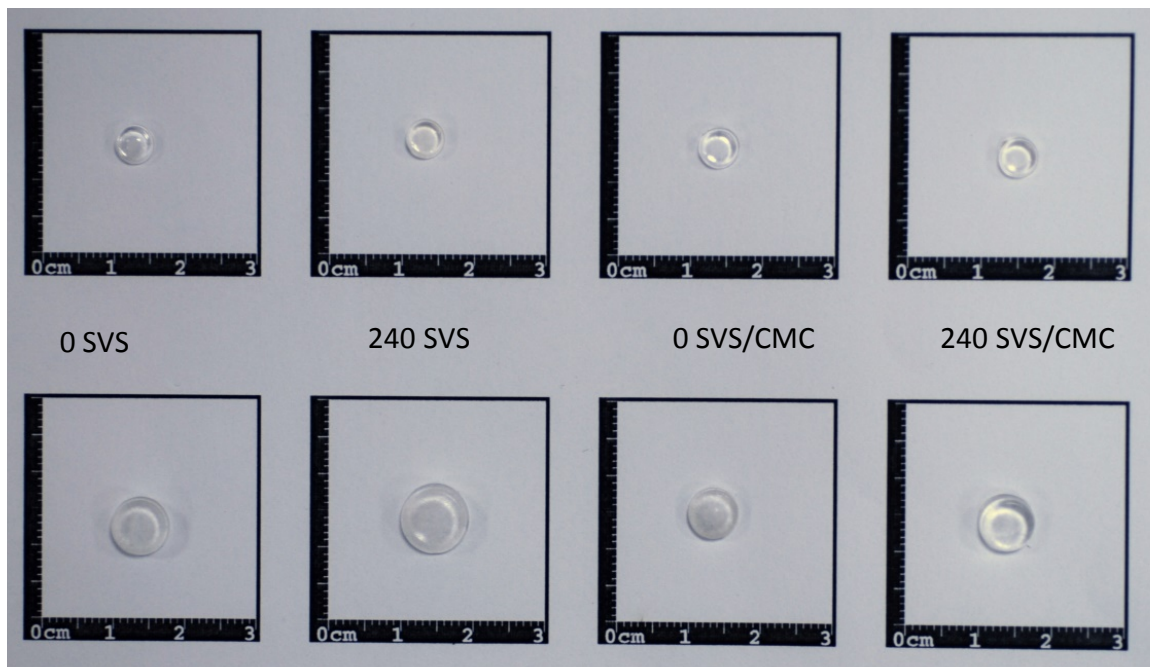

Figure 4. The digital camera images of AAm/SVS hydrogels and AAm/SVS/CMC semi IPN hydrogels (as dry state or swollen state in binary mixtures of water-60\% of THF).

The water or binary mixtures of various compositions of water-solvent (ACE, MET and THF) intake of initially the hydrogels were followed for a period of time, gravimetrically. The swelling factor $(S)$ of the hydrogels in distilled binary mixtures of various compositions of water-solvent (ACE, MET and THF) was calculated from the following relation [5] [20].

$$
S=\frac{m_{t}-m_{o}}{m_{o}}
$$

Here, $m_{t}$ is the mass of the swollen gel at time $t$ and $m_{o}$ is the mass of the dry gel at time 0 . The liquid intake of initially dry hydrogels was followed for novel AAm/SVS hydrogels, AAm/SVS/CMC semi IPNs, AAm/SVS/ZEO hybrid hydrogels, and AAm/SVS/CMC/ZEO biohybrid hydrogels crosslinked by PEGDA in water or binary mixtures of various compositions of water-solvent (ACE, MET and THF), and swelling isotherms of AAm/SVS hydrogels in water-60\% of MET have shown in Figure 5 as representative. As shown in Figure 5, AAm/SVS hydrogels have the lower swelling factor (S) values in water- $60 \%$ of MET.

Figure 5 shows that swelling, or sorption of liquid (water/or binary mixtures of the solvents) increases with time up to certain level, and then levels off. This value of swelling factor $(S)$ may be called as the "equilibrium swelling factor" $\left(S_{e q}\right) . S_{e q}$ values of the hydrogel systems are given in Table 2 . Table 2 shows that $S_{e q}$ of AAm hydrogels is 7.724, but $S_{e q}$ of AAm/SVS hydrogels are $9.082-26.069$ with the incorporation of SVS groups into chemically crosslinked AAm copolymers, if AAm/SVS hydrogels have been swollen in binary mixture of water-60\% of ACE. The other $S_{e q}$ values of the hydrogels have been presented in Table 2 for binary mixture of water- $60 \%$ of MET and binary mixture of water- $60 \%$ of THF, too.

In Table 2, $S_{e q}$ of the hydrogels increased with SVS content in the hydrogel systems. Hydrophilicity of SVS molecules becomes greater than that of AAm, so, 


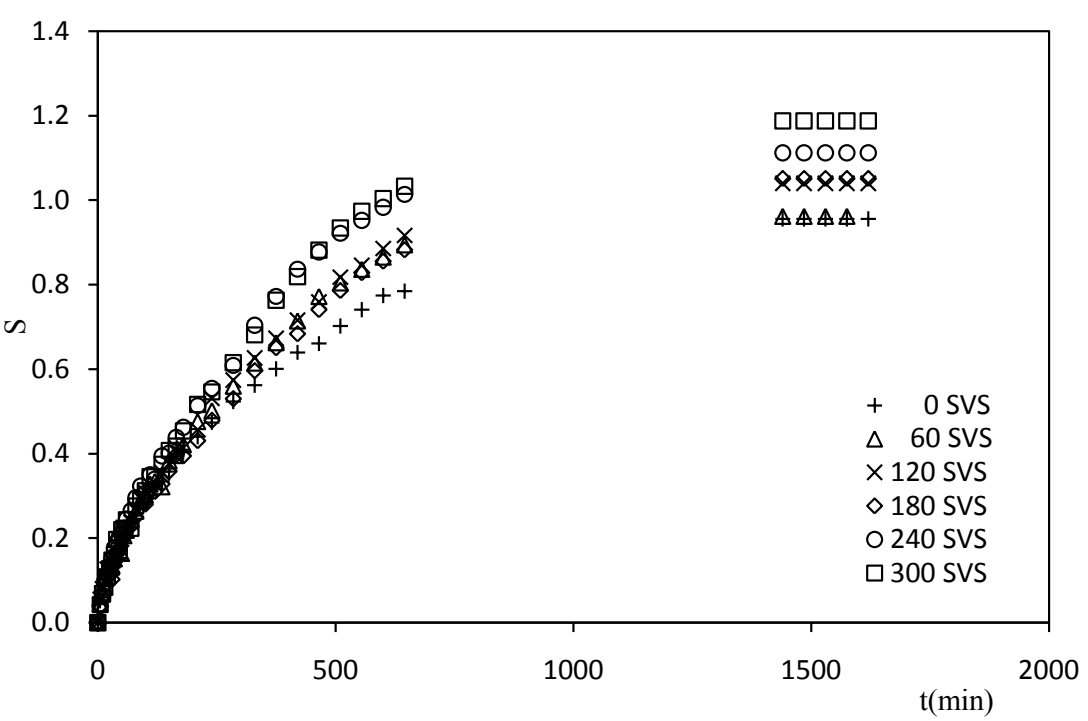

Figure 5. Swelling isotherms of AAm/SVS hydrogels in binary mixtures of water- $60 \%$ of MET.

Table 2. The values of the equilibrium swelling factor $\left(S_{e q}\right)$ in water or binary mixture of water-solvent (ACE, MET and THF).

\begin{tabular}{|c|c|c|c|c|c|c|}
\hline$S V S / \mu \mathrm{L}$ & 0 & 60 & 120 & 180 & 240 & 300 \\
\hline & \multicolumn{6}{|c|}{ Equilibrium swelling factor $\left(S_{e q}\right)$} \\
\hline & \multicolumn{6}{|c|}{ Water } \\
\hline AAm/SVS & 7.724 & 9.082 & 13.095 & 16.779 & 24.607 & 26.069 \\
\hline AAm/SVS/ZEO & 6.614 & 7.980 & 11.533 & 15.469 & 21.690 & 24.989 \\
\hline AAm/SVS/CMC & 7.629 & 10.278 & 13.289 & 15.598 & 22.833 & 31.977 \\
\hline \multirow[t]{2}{*}{ AAm/SVS/CMC/ZEO } & 6.715 & 10.168 & 11.154 & 13.195 & 17.681 & 26.026 \\
\hline & \multicolumn{6}{|c|}{ Water- $60 \%$ of ACE } \\
\hline AAm/SVS & 0.733 & 0.754 & 0.755 & 0.786 & 0.771 & 0.784 \\
\hline AAm/SVS/ZEO & 0.741 & 0.752 & 0.760 & 0.773 & 0.782 & 0.792 \\
\hline AAm/SVS/CMC & 0.811 & 0.792 & 0.782 & 0.762 & 0.748 & 0.700 \\
\hline \multirow[t]{2}{*}{ AAm/SVS/CMC/ZEO } & 0.949 & 0.950 & 0.950 & 0.951 & 0.964 & 0.989 \\
\hline & \multicolumn{6}{|c|}{ Water- $60 \%$ of MET } \\
\hline AAm/SVS & 0.956 & 0.961 & 1.040 & 1.051 & 1.112 & 1.188 \\
\hline AAm/SVS/ZEO & 0.872 & 0.955 & 0.985 & 1.039 & 1.093 & 1.180 \\
\hline $\mathrm{AAm} / \mathrm{SVS} / \mathrm{CMC}$ & 0.986 & 0.994 & 1.040 & 1.067 & 1.196 & 1.366 \\
\hline \multirow[t]{2}{*}{ AAm/SVS/CMC/ZEO } & 0.984 & 1.032 & 1.051 & 1.067 & 1.209 & 1.509 \\
\hline & \multicolumn{6}{|c|}{ Water- $60 \%$ of THF } \\
\hline AAm/SVS & 1.309 & 1.314 & 1.349 & 1.420 & 1.443 & 1.453 \\
\hline AAm/SVS/ZEO & 1.368 & 1.421 & 1.482 & 1.525 & 1.536 & 1.573 \\
\hline AAm/SVS/CMC & 1.306 & 1.330 & 1.354 & 1.368 & 1.766 & 2.215 \\
\hline AAm/SVS/CMC/ZEO & 1.288 & 1.319 & 1.359 & 1.397 & 1.483 & 1.611 \\
\hline
\end{tabular}


the swelling of AAm/SVS is greater than the swelling of AAm hydrogels. AAm/SVS hydrogels strong electrostatic interactions are present due to strongly dissociated charged groups of SVS units [20]. SVS contains many ionic units (Figure 2). The swelling increase is due to an increase in the anionic units. Here, the main effect is the hydrophilic character of SVS. It is well known that the swelling of a hydrogel is induced by the electrostatic repulsion of the ionic charges of its network. The ionic charge content is important. The salt group is almost completely ionized, and a large number of hydrophilic group occur [20].

$S_{e q}$ of AAm/SVS/ZEO hybrid hydrogels containing $1.0 \%$ of ZEO is $7.980-$ 24.989 with the incorporation of ZEO groups into AAm/SVS hydrogels, while $S_{e q}$ of AAm/ZEO hybrid hydrogels is 6.614. On the other hand, the values of $S_{e q}$ of AAm/SVS/CMC semi IPNs containing 1.0\% of CMC are $10.278-31.977$ with the incorporation of CMC into AAm/SVS hydrogels, while $S_{e q}$ of AAm/CMC semi IPNs is 7.629 in water [20]. When solvent and water are mixed, it was seen that important decreasing at swelling values. Table 2 shows that the value of $S_{e q}$ of the hydrogels is $0.733-0.989$ for water- $60 \%$ of ACE, $0.872-1.509$ for water- $60 \%$ of MET, and $1.288-2.215$ for water- $60 \%$ of THF.

The values of $S_{e q}$ of AAm/SVS/CMC/ZEO biohybrid hydrogels containing $1.0 \%$ of $C M C$ and $1.0 \%$ of ZEO are 10.168-26.026 with the incorporation of $\mathrm{CMC}$ and ZEO into AAm/SVS hydrogels, while $S_{e q}$ of AAm/ZEO/CMC biohybrid hydrogels is 6.715 (Table 2). In Table 2, the values of $S_{e q}$ of the hydrogels increased with the SVS content in the crosslinked copolymers. $S_{e q}$ of AAm/SVS hydrogels, AAm/SVS/CMC semi IPNs, AAm/SVS/ZEO hybrid hydrogels, and AAm/SVS/CMC/ZEO biohybrid hydrogels are higher than $S_{e q}$ of AAm hydrogels. Also, this hydrophilic effect has been shown in our previous studies using some hydrophilic co-monomers such as sodium acrylate [21], 2-acrylamido2-methyl-1-propanesulfonic acid [22], 4-styrenesulfonic acid sodium salt [23], and maleic acid [24]. In these studies, the swelling or water sorption increase is due to an increase in the anionic units [5] [20] [21] [22] [23] [24]. It is well known that the swelling of a hydrogel is induced by electrostatic repulsion of the ionic charges of its network. The salt group is almost completely ionized, and a large number of hydrophilic groups occur. An anionic co-monomer such as SVS contains ionizable groups, so more SVS groups on the copolymeric chain contain many ionizable groups. The hydrophilic group numbers of AAm/SVS hydrogels, AAm/SVS/CMC semi IPNs, AAm/SVS/ZEO hybrid hydrogels, and $\mathrm{AAm} / \mathrm{SVS} / \mathrm{CMC} / \mathrm{ZEO}$ biohybrid hydrogels are higher than those of AAm, and so, the values of $S_{e q}$ of AAm/SVS hydrogels, AAm/SVS/CMC semi IPNs, AAm/ SVS/ZEO hybrid hydrogels, and AAm/SVS/CMC/ZEO biohybrid hydrogels were greater than that of the values of $S_{e q}$ of AAm [5] [20] [21] [22] [23] [24].

It was shown that a partially decrease of the values of $S_{e q}$ of AAm/SVS/CMC semi IPNs, AAm/SVS/ZEO hybrid hydrogels, and AAm/SVS/CMC/ZEO biohybrid hydrogels when CMC and ZEO have been added to the hydrogel systems. Incorporation of CMC and ZEO into the copolymer network leads to lower degrees of swelling in water [20]. The reason of this may be the polymeric structure 
of CMC and structure of ZEO. Here, it could be said that a lot of number of group of CMC and/or ZEO chains were placed in the crosslinked polymeric systems, instead of crosslinked AAm and SVS monomers. So, it was seen that decreasing of the value of $S_{e q}$, because of decreasing of partially hydrophilic character at crosslinked polymeric systems. But, on the other hand, it can be said that there is no good relationship between the values of $S_{e q}$ of the hydrogels, when CMC and/or ZEO have been added to the polymeric systems [20]. The same characteristic swelling behavior and results could have been followed, if there have been investigated that the results of swelling studies of the hydrogels in binary mixtures of various compositions of water-solvent (ACE, MET and THF). Again here, it can be said that there was no good relationship between the values of $S_{e q}$ of the hydrogels, when CMC and/or ZEO have been added to the polymeric systems.

For understanding the effect of SVS content on the swelling behavior in water, in water- $60 \%$ of ACE, in water- $60 \%$ of MET and in water- $60 \%$ of THF, the values of $S_{e q}$ of the hydrogels versus the content of SVS is plotted in Figures 6-9. In Figures 6-9, the values of $S_{e q}$ of the hydrogels gradually increased with increasing of SVS content in the hydrogels.

\subsection{Equilibrium Water/Liquid Capacity}

The water or liquid absorbed by AAm/SVS hydrogels, AAm/SVS/CMC semi IPNs, AAm/SVS/ZEO hybrid hydrogels and AAm/SVS/CMC/ZEO biohybrid hydrogels quantitatively represented by equilibrium water/liquid capacity (EWLC) also, and they can be calculated by below equation [25] [26] [27].

$$
\mathrm{EWLC}=\frac{m_{e q}-m_{o}}{m_{e q}}
$$

Here, $m_{e q}$ is the mass of the swollen gel at time $t$ (equilibrium), and $m_{o}$ is the mass of the dry gel at time 0 . The values of EWLC of the hydrogel systems were

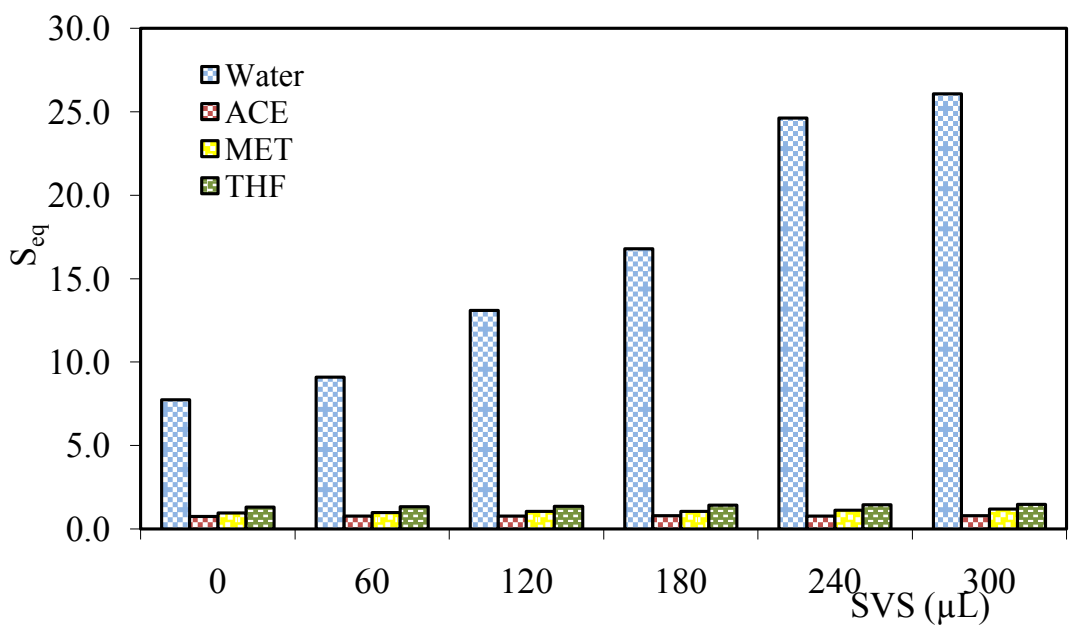

Figure 6. Effect of the content of SVS onto swelling of AAm/SVS hydrogels in water, in binary mixtures of water- $60 \%$ of ACE, in water- $60 \%$ of MET and in water- $60 \%$ of THF. 


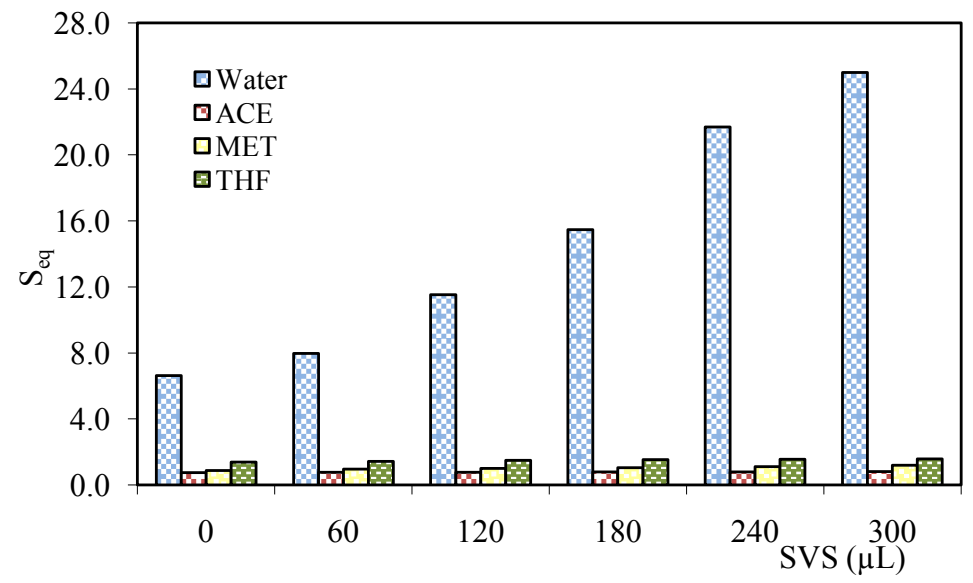

Figure 7. Effect of the content of SVS onto swelling of AAm/SVS/ZEO hybrid hydrogels (containing of $1.0 \% \mathrm{ZEO}$ ) in water, in binary mixtures of water-60\% of ACE, in water- $60 \%$ of MET and in water- $60 \%$ of THF.

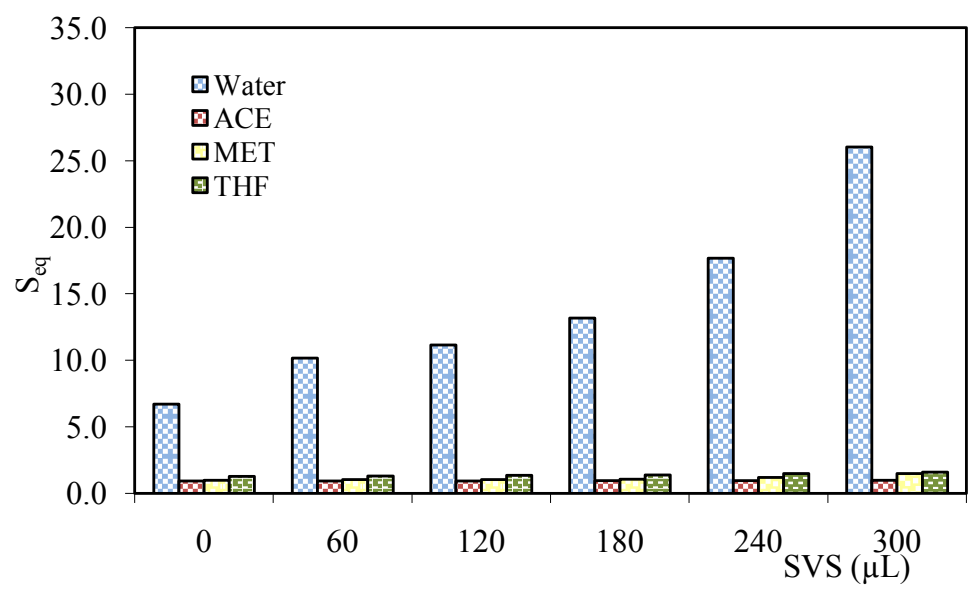

Figure 8. Effect of the content of SVS onto swelling of AAm/SVS/CMC semi IPN hydrogels (containing of $1.0 \% \mathrm{CMC}$ ) in water, in binary mixtures of water-60\% of ACE, in water- $60 \%$ of MET and in water- $60 \%$ of THF.

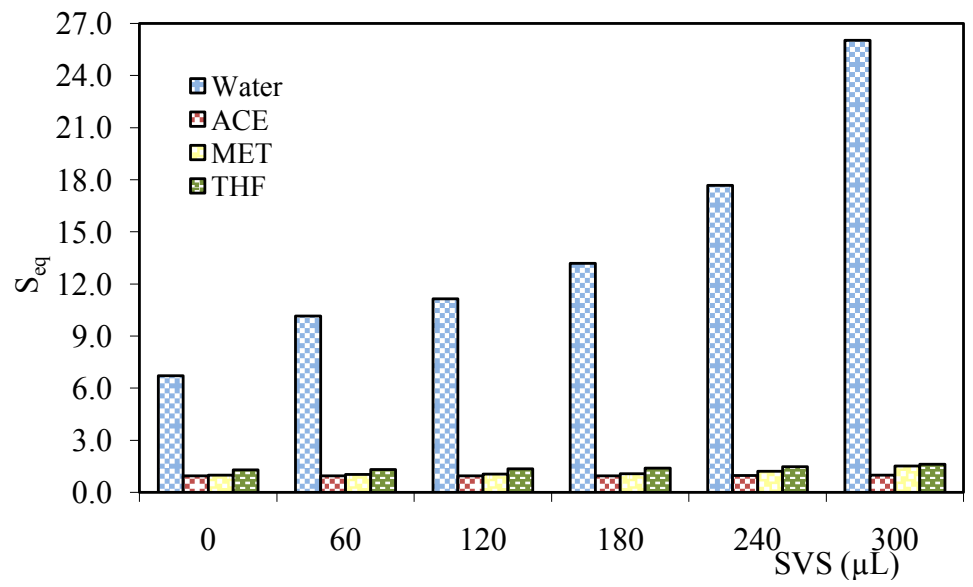

Figure 9. Effect of the content of SVS onto swelling of AAm/SVS/CMC/ZEO biohybrid hydrogels (containing of $1.0 \%$ CMC and $1.0 \%$ ZEO) in water, in binary mixtures of water- $60 \%$ of ACE, in water- $60 \%$ of MET and in water- $60 \%$ of THF. 
calculated. These values of EWLC of the hydrogels are tabulated in Table 3. They are changed between $0.4118-0.9697$. It is seen that an increasing of the values of EWLC, if SVS has been added to the hydrogel systems. Here, the main effect is the hydrophilic character of SVS groups. But, it has been seen that increasing of the values of EWLC, if CMC and/or ZEO have been added to the hydrogel systems if there have been investigated that the values of EWLC of the hydrogels in binary mixtures of various compositions of water-solvent (ACE, MET and THF). Again here, it can be said that there was no good relationship between the values of EWLC of the hydrogels, when CMC and/or ZEO have been added to the polymeric systems.

Here, the main effect is the hydrophilic character of SVS monomer and non-hydrophilic character of the solvents as mentioned before then.

\subsection{Diffusion of Water or Water-Solvent Binary Mixtures}

Diffusion involves migration of water or water-solvent binary mixtures into pre-existing or dynamically formed spaces between hydrogel chains. Swelling of

Table 3. The values of the equilibrium water/liquid capacity (EWLC) of the hydrogel systems in water or binary mixture of water-solvent (ACE, MET and THF).

\begin{tabular}{|c|c|c|c|c|c|c|}
\hline $\mathrm{SVS} / \mu \mathrm{L}$ & 0 & 60 & 120 & 180 & 240 & 300 \\
\hline & \multicolumn{6}{|c|}{ Equilibrium water/liquid capacity (EWLC) } \\
\hline & \multicolumn{6}{|c|}{ Water } \\
\hline AAm/SVS & 0.8854 & 0.9008 & 0.9291 & 0.9438 & 0.9609 & 0.9631 \\
\hline AAm/SVS/ZEO & 0.8687 & 0.8886 & 0.9202 & 0.9393 & 0.9559 & 0.9615 \\
\hline AAm/SVS/CMC & 0.8841 & 0.9113 & 0.9300 & 0.9398 & 0.9580 & 0.9697 \\
\hline \multirow[t]{2}{*}{ AAm/SVS/CMC/ZEO } & 0.8704 & 0.9105 & 0.9177 & 0.9296 & 0.9465 & 0.9630 \\
\hline & \multicolumn{6}{|c|}{ Water- $60 \%$ of ACE } \\
\hline $\mathrm{AAm} / \mathrm{SVS}$ & 0.4230 & 0.4298 & 0.4302 & 0.4399 & 0.4352 & 0.4396 \\
\hline AAm/SVS/ZEO & 0.4257 & 0.4291 & 0.4319 & 0.4359 & 0.4387 & 0.4419 \\
\hline AAm/SVS/CMC & 0.4477 & 0.4419 & 0.4389 & 0.4323 & 0.4279 & 0.4118 \\
\hline \multirow[t]{2}{*}{ AAm/SVS/CMC/ZEO } & 0.4868 & 0.4871 & 0.4871 & 0.4874 & 0.4908 & 0.4973 \\
\hline & \multicolumn{6}{|c|}{ Water- $60 \%$ of MET } \\
\hline $\mathrm{AAm} / \mathrm{SVS}$ & 0.4887 & 0.4902 & 0.5098 & 0.5125 & 0.5266 & 0.5429 \\
\hline AAm/SVS/ZEO & 0.4659 & 0.4884 & 0.4962 & 0.5095 & 0.5222 & 0.5414 \\
\hline AAm/SVS/CMC & 0.4966 & 0.4985 & 0.5099 & 0.5162 & 0.5447 & 0.5773 \\
\hline \multirow[t]{2}{*}{ AAm/SVS/CMC/ZEO } & 0.4959 & 0.5079 & 0.5124 & 0.5163 & 0.5472 & 0.6014 \\
\hline & \multicolumn{6}{|c|}{ Water- $60 \%$ of THF } \\
\hline AAm/SVS & 0.5668 & 0.5679 & 0.5742 & 0.5869 & 0.5907 & 0.5924 \\
\hline AAm/SVS/ZEO & 0.5777 & 0.5870 & 0.5972 & 0.6040 & 0.6057 & 0.6114 \\
\hline $\mathrm{AAm} / \mathrm{SVS} / \mathrm{CMC}$ & 0.5663 & 0.5708 & 0.5753 & 0.5776 & 0.6385 & 0.6889 \\
\hline AAm/SVS/CMC/ZEO & 0.5630 & 0.5689 & 0.5762 & 0.5828 & 0.5973 & 0.6171 \\
\hline
\end{tabular}


the hydrogel involves larger segmental motion resulting, ultimately, in increased separation between hydrogel chains. When a glassy hydrogel is brought into contact with water or water-solvent mixtures, water or water-solvent mixtures diffuses into the hydrogel and the network expands resulting in swelling of the hydrogel.

Analysis of the mechanisms of water or water-solvent binary mixtures diffusion into swellable polymeric systems has received considerable attention in recent years, because of important applications of swellable polymers in biomedical, pharmaceutical, environmental, and agricultural processing. The following equation is used to determine the nature of diffusion of water or water-solvent mixtures into hydrogels [27] [28] [29].

$$
F=\frac{M_{t}}{M_{s}}=k t^{n}
$$

Here, $F$ is the fractional uptake at time $t, M_{t}$ and $M_{s}$ are the mass uptake of the water or water-solvent mixtures at time $t$ and the equilibrium, respectively. Equation (3) is valid for the first $60 \%$ of the fractional uptake. Fickian diffusion and Case II transport are defined by $n$ values of 0.5 and 1.0, respectively. Anomalous transport behavior (non-Fickian diffusion) is intermediate between Fickian and Case II. That is reflected by $\mathrm{n}$ between (0.5) and (1.0) [28] [29]. The values of $n$ and $k$ were calculated from the slope and the intercept of the plot of $\ln F$ against lnt, respectively.

For chemically crosslinked highly swollen AAm/SVS hydrogels, AAm/SVS/CMC semi IPNs, AAm/SVS/ZEO hybrid hydrogels, and AAm/SVS/CMC/ZEO biohybrid hydrogels, the plots of $\ln F$ vs. $\ln t$ where $F$ is equal to $\left(M_{t} / M_{s}\right)$ are shown in Figure 10 for AAm/SVS/ZEO hybrid hydrogels in water-60\% of ACE, as representative. Diffusional exponents $(n)$ and diffusion constant $(k)$ are calculated from the slopes and intercepts of the lines, respectively, and are listed in Tables 4-6.

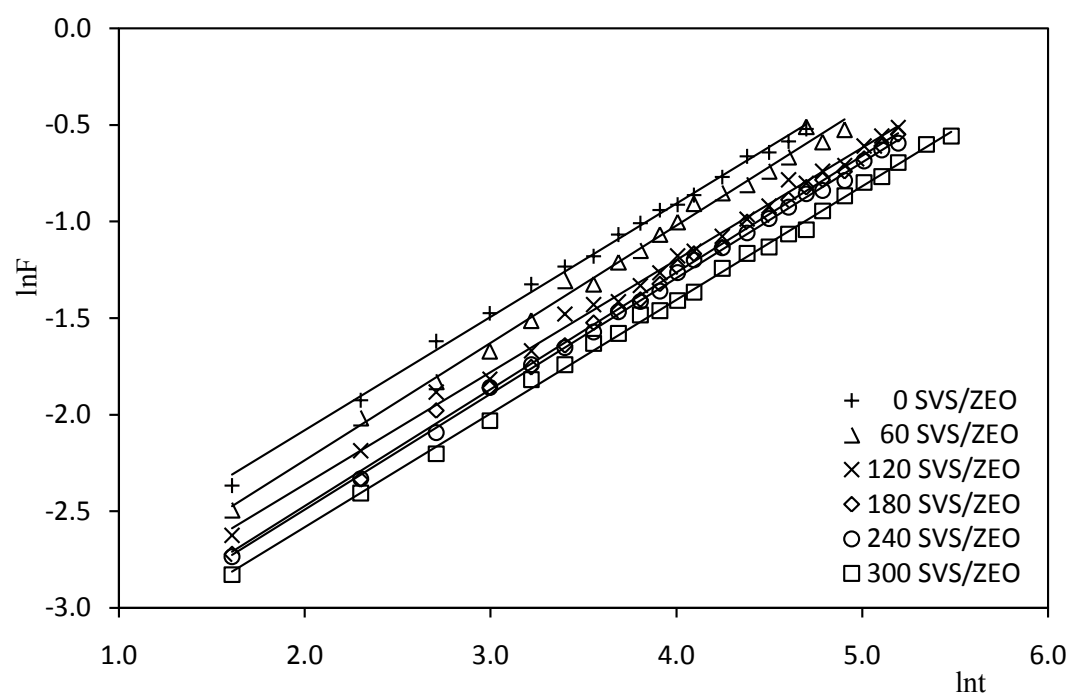

Figure 10. Plots of $\ln F$ versus $\ln t$ for AAm/SVS/ZEO biohybrid hydrogels in binary mixture water- $60 \%$ of ACE. 
Table 4. Some diffusion parameters of the hydrogels in water- $60 \%$ of ACE.

\begin{tabular}{|c|c|c|c|c|c|c|}
\hline $\mathrm{SVS} / \mu \mathrm{L}$ & 0 & 60 & 120 & 180 & 240 & 300 \\
\hline & \multicolumn{6}{|c|}{ Water- $60 \%$ of ACE } \\
\hline & \multicolumn{6}{|c|}{ Diffusion exponent $(n)$} \\
\hline $\mathrm{AAm} / \mathrm{SVS}$ & 0.5294 & 0.5874 & 0.5439 & 0.5288 & 0.5884 & 0.5802 \\
\hline AAm/SVS/ZEO & 0.5862 & 0.6076 & 0.5804 & 0.6044 & 0.5992 & 0.5881 \\
\hline $\mathrm{AAm} / \mathrm{SVS} / \mathrm{CMC}$ & 0.5003 & 0.5780 & 0.5579 & 0.5881 & 0.5698 & 0.5764 \\
\hline \multirow[t]{2}{*}{ AAm/SVS/CMC/ZEO } & 0.5717 & 0.5511 & 0.5836 & 0.5817 & 0.6226 & 0.5517 \\
\hline & \multicolumn{6}{|c|}{ Diffusion constant $\left(k \times 10^{2}\right)$} \\
\hline AAm/SVS & 4.408 & 2.638 & 3.414 & 3.367 & 2.780 & 2.762 \\
\hline AAm/SVS/ZEO & 3.869 & 3.169 & 2.957 & 2.518 & 2.500 & 2.332 \\
\hline $\mathrm{AAm} / \mathrm{SVS} / \mathrm{CMC}$ & 5.508 & 3.258 & 3.472 & 2.970 & 2.953 & 2.956 \\
\hline \multirow[t]{2}{*}{ AAm/SVS/CMC/ZEO } & 2.640 & 2.497 & 2.620 & 2.165 & 1.919 & 2.677 \\
\hline & \multicolumn{6}{|c|}{ Diffusion coefficient $\left(D \times 10^{5}\right)$} \\
\hline AAm/SVS & 5.333 & 5.794 & 6.134 & 5.129 & 9.726 & 9.628 \\
\hline AAm/SVS/ZEO & 8.821 & 13.870 & 9.276 & 11.155 & 10.276 & 8.002 \\
\hline $\mathrm{AAm} / \mathrm{SVS} / \mathrm{CMC}$ & 5.442 & 8.515 & 7.745 & 9.269 & 7.634 & 5.747 \\
\hline \multirow[t]{2}{*}{$\mathrm{AAm} / \mathrm{SVS} / \mathrm{CMC} / \mathrm{ZEO}$} & 4.134 & 4.205 & 8.458 & 6.783 & 7.998 & 5.140 \\
\hline & \multicolumn{6}{|c|}{ Water/liquid sorption rate constant $\left(K_{s r} \times 10^{3}\right)$} \\
\hline AAm/SVS & 5.717 & 3.983 & 4.550 & 3.932 & 4.432 & 4.064 \\
\hline AAm/SVS/ZEO & 7.310 & 6.516 & 4.595 & 4.327 & 4.082 & 3.327 \\
\hline $\mathrm{AAm} / \mathrm{SVS} / \mathrm{CMC}$ & 6.813 & 5.029 & 5.001 & 5.115 & 4.161 & 4.386 \\
\hline $\mathrm{AAm} / \mathrm{SVS} / \mathrm{CMC} / \mathrm{ZEO}$ & 3.089 & 2.954 & 4.005 & 3.053 & 3.235 & 3.030 \\
\hline
\end{tabular}

Table 5. Some diffusion parameters of the hydrogels in water-60\% of MET.

\begin{tabular}{|c|c|c|c|c|c|c|}
\hline $\mathrm{SVS} / \mu \mathrm{L}$ & 0 & 60 & 120 & 180 & 240 & 300 \\
\hline & \multicolumn{6}{|c|}{ Water- $60 \%$ of MET } \\
\hline & \multicolumn{6}{|c|}{ Diffusion exponent (n) } \\
\hline AAm/SVS & 0.5741 & 0.6236 & 0.5805 & 0.6264 & 0.6564 & 0.6525 \\
\hline AAm/SVS/ZEO & 0.6360 & 0.6217 & 0.6602 & 0.5966 & 0.6095 & 0.6359 \\
\hline AAm/SVS/CMC & 0.5796 & 0.6758 & 0.6461 & 0.6407 & 0.6386 & 0.6629 \\
\hline \multirow[t]{2}{*}{ AAm/SVS/CMC/ZEO } & 0.6133 & 0.6526 & 0.6668 & 0.6676 & 0.6579 & 0.7241 \\
\hline & \multicolumn{6}{|c|}{ Diffusion constant $\left(k \times 10^{2}\right)$} \\
\hline AAm/SVS & 2.134 & 1.733 & 2.001 & 1.509 & 1.416 & 1.311 \\
\hline AAm/SVS/ZEO & 2.262 & 2.188 & 1.567 & 2.080 & 1.712 & 1.503 \\
\hline AAm/SVS/CMC & 3.369 & 1.377 & 1.484 & 1.359 & 1.346 & 1.158 \\
\hline \multirow[t]{2}{*}{ AAm/SVS/CMC/ZEO } & 2.050 & 1.326 & 1.230 & 1.096 & 1.110 & 0.752 \\
\hline & \multicolumn{6}{|c|}{ Diffusion coefficient $\left(D \times 10^{5}\right)$} \\
\hline
\end{tabular}




\section{Continued}

\begin{tabular}{ccccccc}
\hline AAm/SVS & 5.159 & 7.677 & 5.468 & 7.044 & 9.955 & 9.647 \\
AAm/SVS/ZEO & 10.714 & 8.949 & 9.334 & 6.249 & 5.786 & 6.096 \\
AAm/SVS/CMC & 7.447 & 9.021 & 9.476 & 7.693 & 7.684 & 8.433 \\
AAm/SVS/CMC/ZEO & 7.198 & 7.125 & 8.375 & 8.146 & 7.592 & 10.947 \\
& & Water/liquid sorption rate constant $\left(K_{s r} \times 10^{3}\right)$ & \\
AAm/SVS & 2.487 & 2.824 & 2.553 & 2.279 & 2.583 & 2.390 \\
AAm/SVS/ZEO & 4.332 & 3.909 & 2.873 & 2.923 & 2.319 & 2.512 \\
AAm/SVS/CMC & 6.188 & 3.035 & 2.570 & 2.168 & 2.115 & 2.034 \\
AAm/SVS/CMC/ZEO & 3.318 & 2.354 & 2.302 & 2.062 & 1.985 & 1.887 \\
\hline
\end{tabular}

Table 6. Some diffusion parameters of the hydrogels in water- $60 \%$ of THF.

\begin{tabular}{|c|c|c|c|c|c|c|}
\hline $\mathrm{SVS} / \mu \mathrm{L}$ & 0 & 60 & 120 & 180 & 240 & 300 \\
\hline & \multicolumn{6}{|c|}{ Water- $60 \%$ of THF } \\
\hline & \multicolumn{6}{|c|}{ Diffusion exponent $(n)$} \\
\hline $\mathrm{AAm} / \mathrm{SVS}$ & 0.5691 & 0.5626 & 0.5680 & 0.5342 & 0.5569 & 0.5666 \\
\hline AAm/SVS/ZEO & 0.5909 & 0.5507 & 0.5642 & 0.5658 & 0.5746 & 0.5851 \\
\hline $\mathrm{AAm} / \mathrm{SVS} / \mathrm{CMC}$ & 0.5765 & 0.5741 & 0.5447 & 0.5550 & 0.5405 & 0.5294 \\
\hline \multirow[t]{2}{*}{$\mathrm{AAm} / \mathrm{SVS} / \mathrm{CMC} / \mathrm{ZEO}$} & 0.5090 & 0.5265 & 0.5141 & 0.5372 & 0.5164 & 0.5215 \\
\hline & \multicolumn{6}{|c|}{ Diffusion constant $\left(k \times 10^{2}\right)$} \\
\hline AAm/SVS & 4.743 & 4.793 & 3.411 & 3.795 & 3.653 & 3.092 \\
\hline AAm/SVS/ZEO & 3.182 & 3.222 & 3.157 & 2.718 & 2.719 & 2.811 \\
\hline AAm/SVS/CMC & 5.753 & 4.026 & 3.984 & 3.750 & 2.660 & 2.182 \\
\hline \multirow[t]{2}{*}{$\mathrm{AAm} / \mathrm{SVS} / \mathrm{CMC} / \mathrm{ZEO}$} & 5.498 & 4.235 & 4.293 & 3.983 & 3.694 & 3.610 \\
\hline & \multicolumn{6}{|c|}{ Diffusion coefficient $\left(D \times 10^{5}\right)$} \\
\hline AAm/SVS & 16.616 & 18.083 & 11.899 & 10.652 & 14.477 & 12.592 \\
\hline AAm/SVS/ZEO & 11.725 & 8.102 & 10.586 & 9.216 & 11.033 & 15.497 \\
\hline $\mathrm{AAm} / \mathrm{SVS} / \mathrm{CMC}$ & 20.131 & 11.986 & 10.098 & 12.232 & 5.976 & 3.962 \\
\hline \multirow[t]{2}{*}{ AAm/SVS/CMC/ZEO } & 10.291 & 9.867 & 8.820 & 11.889 & 7.487 & 8.296 \\
\hline & \multicolumn{6}{|c|}{ Water/liquid sorption rate constant $\left(K_{s r} \times 10^{3}\right)$} \\
\hline AAm/SVS & 9.458 & 9.213 & 4.905 & 4.621 & 5.361 & 4.344 \\
\hline AAm/SVS/ZEO & 5.557 & 4.071 & 4.555 & 3.388 & 3.786 & 4.372 \\
\hline AAm/SVS/CMC & 13.789 & 7.372 & 5.613 & 5.653 & 2.766 & 1.424 \\
\hline $\mathrm{AAm} / \mathrm{SVS} / \mathrm{CMC} / \mathrm{ZEO}$ & 7.461 & 5.257 & 4.779 & 5.256 & 3.853 & 3.647 \\
\hline
\end{tabular}

Tables 4-6 show that the values of the number determining the type of diffusion $(n)$ are between $0.5003-0.6758$. Hence the diffusion of binary mixtures of water-solvent (60\% of solvent (ACE, MET and THF) of various compositions into the hydrogel systems is generally found to have a non-Fickian character. 
When the diffusion type is anomalous behavior, the relaxation and diffusion time are of the same order of magnitude [28] [29]. Tables 4-6 show that the number determining the type of diffusion, $\mathrm{n}$ is over 0.50 . Hence the diffusion of water or water-solvent mixtures into the hydrogels is generally found to have a non-Fickian character [28] [29]. When the diffusion type is anomalous behavior, the relaxation and diffusion time are of the same order of magnitude [28] [29].

The study of diffusion phenomena of water or water-solvent binary mixtures in hydrogels is of value in that it clarifies polymer behavior. For hydrogel characterization, the diffusion coefficients can be calculated by various methods. The diffusion coefficient, $D$ of the water or water-solvent mixtures was calculated using the following equation [30] [31].

$$
D=\pi r^{2}\left(\frac{k}{4}\right)^{1 / n}
$$

Here $D$ is in $\mathrm{cm}^{2} \cdot \mathrm{s}^{-1}, r$ is the radius of a cylindrical polymer sample, $n$ is the diffusional exponent and $k$ is a constant incorporating characteristic of the macromolecular network system and the penetrant. The values of diffusion coefficient determined for the hydrogels are listed in Tables 4-6. Tables 4-6 show that the values of the diffusion coefficient of AAm/SVS hydrogels, AAm/SVS/CMC semi IPNs, AAm/SVS/ZEO hybrid hydrogels, and AAm/SVS/CMC/ZEO biohybrid hydrogels vary from $1.59 \times 10^{-4} \mathrm{~cm}^{2} \cdot \mathrm{s}^{-1}$ to $8.34 \times 10^{-4} \mathrm{~cm}^{2} \cdot \mathrm{s}^{-1}$ for water [20], but the values of the diffusion coefficient of AAm/SVS hydrogels, AAm/SVS/CMC semi IPNs, AAm/SVS/ZEO hybrid hydrogels, and AAm/SVS/CMC/ZEO biohybrid hydrogels vary from $3.962 \times 10^{-5} \mathrm{~cm}^{2} \cdot \mathrm{s}^{-1}$ to $20.131 \times 10^{-5} \mathrm{~cm}^{2} \cdot \mathrm{s}^{-1}$ for binary mixtures of water-solvent ( $60 \%$ of ACE, $60 \%$ of MET and $60 \%$ of THF). It can be said that there is no good relationship between the values of the diffusion coefficient of AAm/SVS hydrogels, AAm/SVS/CMC semi IPNs, AAm/SVS/ZEO hybrid hydrogels, and AAm/SVS/CMC/ZEO biohybrid hydrogels for binary mixtures of water-solvent ( $60 \%$ of ACE, $60 \%$ of MET and $60 \%$ of THF).

\subsection{Water/Liquid Sorption Rate}

Other important diffusion parameters can be "water/liquid sorption rate constant" $\left(K_{s r}\right)$. This parameter can be calculated by the presented at below equation [5] [20] [32].

$$
-\ln (1-F)=K_{s r} t+E
$$

where $t$ is sorption time, " $K_{s r}$ " is water/liquid sorption rate constant. $F$ was described before, and $E$ is a constant. For chemically crosslinked highly swollen AAm/SVS hydrogels, AAm/SVS/CMC semi IPNs, AAm/SVS/ZEO hybrid hydrogels, and AAm/SVS/CMC/ZEO biohybrid hydrogels, the plots of $[-\ln (1-F)]$ $v s[t]$ where $F$ is equal to $\left(M_{t} / M_{s}\right)$ are shown in Figure 11 for AAm/SVS/ZEO hybrid hydrogels in water- $60 \%$ of $\mathrm{ACE}$, as representative.

The water sorption rate constants of AAm/SVS hydrogels, AAm/SVS/CMC semi IPNs, AAm/SVS/ZEO hybrid hydrogels, and AAm/SVS/CMC/ZEO biohybrid 


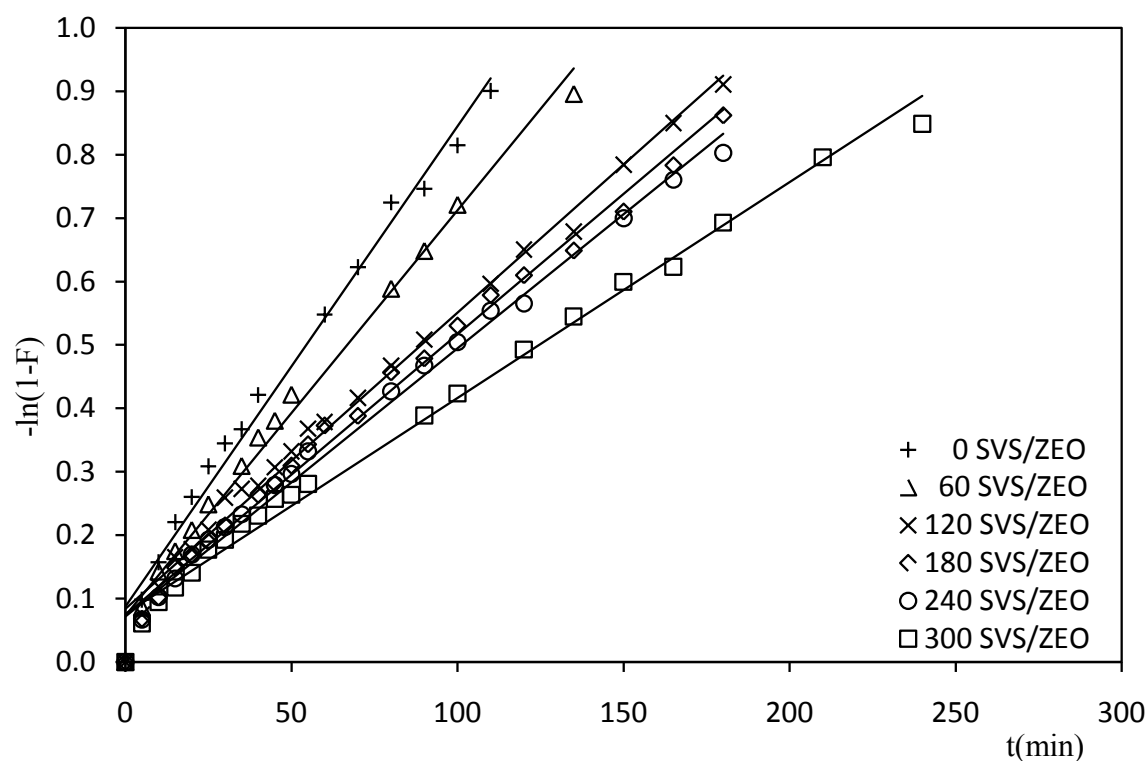

Figure 11. Plots of $-\ln (1-F)$ versus $\ln t$ for AAm/SVS/ZEO biohybrid hydrogels in binary mixture water $-60 \%$ of ACE.

hydrogels calculated from the slope of the plots, and they are tabulated at Tables 4-6. They are changed among range vary from $1.424 \times 10^{-3} \mathrm{~min}^{-1}$ to $13.7890 \times$ $10^{-3} \mathrm{~min}^{-1}$. Tables 4-6 showed that water/liquid sorption rate constants of AAm/ SVS hydrogels, AAm/SVS/CMC semi IPNs, AAm/SVS/ZEO hybrid hydrogels, and AAm/SVS/CMC/ZEO biohybrid hydrogels are generally lower than that of AAm hydrogels, AAm/CMC semi IPNs, AAm/ZEO hybrid hydrogels, and AAm/CMC/ZEO biohybrid hydrogels. The reason of this may be the hydrophilic and ionic characteristics of SVS. Every SVS molecule has got an anionic group such as vinylsulfonate group having negative charge. Because of the more charged structure, water sorption into the hydrogel systems may be irregular. On the other hand, it can be said that more irregular forms could be occurred in cross-linked structure by adding of CMC and/or ZEO.

\subsection{CMC and ZEO Effect on Swelling and Diffusion}

For investigation of the effect of mass/content of CMC and ZEO on the swelling and diffusional properties of AAm/SVS hydrogels, AAm/SVS/CMC semi IPNs, AAm/SVS/ZEO hybrid hydrogels, and AAm/SVS/CMC/ZEO biohybrid hydrogels, the related swelling isotherms and related swelling kinetic curves of hydrogel systems were constructed and, plots of $\ln F$ versus $\ln t$ for AAm/SVS/CMC semi IPN hydrogels containing $240 \mu \mathrm{L}$ of SVS and different contents of CMC was shown in Figure 12 as representative. Effect of CMC and ZEO on some swelling, kinetics and diffusion parameters of AAm/SVS/CMC semi IPNs and AAm/SVS/ZEO hybrid hydrogels having of $240 \mu \mathrm{L}$ SVS with different volume (as $\mathrm{mL}$ ) of $2.0 \%$ of ZEO-water suspension or $2.0 \%$ of aqueous CMC solutions were tabulated in Table 7 and Table 8 .

It was shown that an increasing of the values of $S_{e q}$ of AAm/SVS/CMC semi 


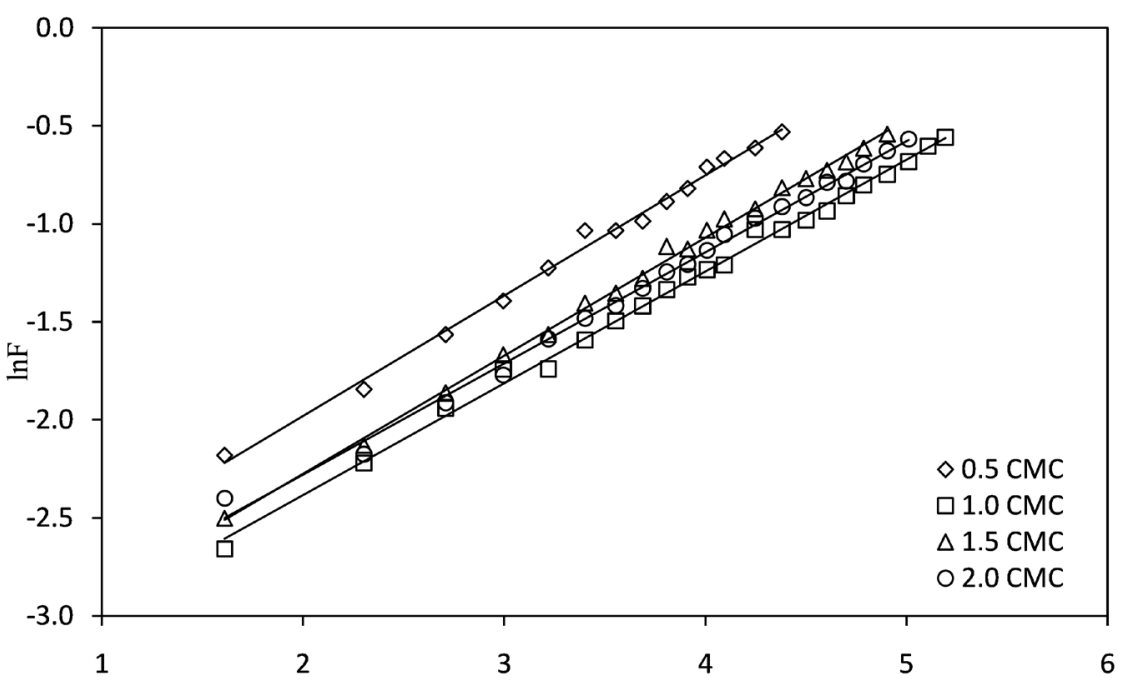

Figure 12. Plots of $\ln F$ versus $\ln t$ for AAm/SVS/CMC semi IPN hydrogels containing 240 $\mu \mathrm{L}$ of SVS and different contents of CMC in the binary mixture of water- $60 \%$ of ACE.

Table 7. Some swelling and diffusion parameters of AAm/SVS/ZEO hydrogels having of $240 \mu \mathrm{L}$ of SVS with different ZEO content.

\begin{tabular}{|c|c|c|c|c|}
\hline $2.0 \%$ of $\mathrm{ZEO}$-water suspension $(\mathrm{mL})$ & 0.25 & 0.50 & 0.75 & 1.00 \\
\hline & \multicolumn{4}{|c|}{ Water } \\
\hline$S_{e q}$ & 18.062 & 21.690 & 22.940 & 25.132 \\
\hline EWLC & 0.9475 & 0.9559 & 0.9582 & 0.9617 \\
\hline$n$ & 0.7229 & 0.7280 & 0.7042 & 0.7148 \\
\hline$k \times 10^{2}$ & 1.292 & 1.215 & 1.184 & 1.009 \\
\hline$D \times 10^{5}$ & 66.238 & 83.868 & 64.116 & 70.197 \\
\hline \multirow[t]{2}{*}{$\left(K_{s r} \times 10^{3}\right)$} & 4.303 & 4.061 & 3.085 & 2.805 \\
\hline & \multicolumn{4}{|c|}{ Water- $60 \%$ of ACE } \\
\hline$S_{e q}$ & 0.780 & 0.782 & 0.818 & 0.831 \\
\hline EWLC & 0.4381 & 0.4387 & 0.4499 & 0.4539 \\
\hline$n$ & 0.5710 & 0.5992 & 0.5573 & 0.5763 \\
\hline$k \times 10^{2}$ & 2.942 & 2.500 & 3.130 & 2.848 \\
\hline$D \times 10^{5}$ & 6.394 & 10.276 & 7.451 & 10.433 \\
\hline \multirow[t]{2}{*}{$\left(K_{s r} \times 10^{3}\right)$} & 4.151 & 4.082 & 4.388 & 4.143 \\
\hline & \multicolumn{4}{|c|}{ Water- $60 \%$ of MET } \\
\hline$S_{e q}$ & 1.083 & 1.093 & 1.151 & 1.122 \\
\hline EWLC & 0.5199 & 0.5222 & 0.5350 & 0.5287 \\
\hline$n$ & 0.6190 & 0.6095 & 0.6062 & 0.6453 \\
\hline$k \times 10^{2}$ & 1.575 & 1.712 & 2.086 & 1.548 \\
\hline$D \times 10^{5}$ & 5.177 & 5.786 & 7.280 & 7.961 \\
\hline \multirow[t]{2}{*}{$\left(K_{s r} \times 10^{3}\right)$} & 2.121 & 2.319 & 3.062 & 2.736 \\
\hline & \multicolumn{4}{|c|}{ Water- $60 \%$ of THF } \\
\hline
\end{tabular}




\section{Continued}

\begin{tabular}{ccccc}
\hline$S_{e q}$ & 1.398 & 1.536 & 1.582 & 1.627 \\
EWLC & 0.5830 & 0.6057 & 0.6128 & 0.6193 \\
$n$ & 0.5828 & 0.5746 & 0.5654 & 0.5250 \\
$k \times 10^{2}$ & 3.505 & 2.719 & 3.137 & 3.820 \\
$D \times 10^{5}$ & 15.466 & 11.033 & 11.093 & 9.095 \\
$\left(K_{s r} \times 10^{3}\right)$ & 6.329 & 3.786 & 4.445 & 4.289 \\
\hline
\end{tabular}

Table 8. Some swelling and diffusion parameters of AAm/SVS/CMC hydrogels having of $240 \mu \mathrm{L}$ of SVS with different CMC content.

\begin{tabular}{|c|c|c|c|c|}
\hline $2.0 \%$ of aq. CMC sol. $(\mathrm{mL})$ & 0.25 & 0.50 & 0.75 & 1.00 \\
\hline & \multicolumn{4}{|c|}{ Water } \\
\hline$S_{e q}$ & 20.831 & 22.833 & 25.625 & 31.276 \\
\hline EWC & 0.9542 & 0.9580 & 0.9624 & 0.9690 \\
\hline$n$ & 0.7472 & 0.6908 & 0.7678 & 0.7043 \\
\hline$k \times 10^{2}$ & 1.336 & 0.932 & 1.105 & 0.965 \\
\hline$D \times 10^{5}$ & 94.190 & 40.954 & 131.580 & 58.336 \\
\hline \multirow[t]{2}{*}{$\left(K_{s r} \times 10^{3}\right)$} & 5.289 & 2.051 & 4.717 & 2.444 \\
\hline & \multicolumn{4}{|c|}{ Water- $60 \%$ of ACE } \\
\hline$S_{e q}$ & 0.738 & 0.748 & 0.765 & 0.788 \\
\hline EWLC & 0.4245 & 0.4279 & 0.4334 & 0.4407 \\
\hline$n$ & 0.6137 & 0.5698 & 0.6022 & 0.5666 \\
\hline$k \times 10^{2}$ & 4.048 & 2.953 & 3.084 & 3.300 \\
\hline$D \times 10^{5}$ & 23.702 & 7.634 & 14.434 & 9.996 \\
\hline \multirow[t]{2}{*}{$\left(K_{s r} \times 10^{3}\right)$} & 10.224 & 4.161 & 5.817 & 5.001 \\
\hline & \multicolumn{4}{|c|}{ Water- $60 \%$ of MET } \\
\hline$S_{e q}$ & 1.283 & 1.196 & 1.216 & 1.255 \\
\hline EWLC & 0.5621 & 0.5447 & 0.5487 & 0.5565 \\
\hline$n$ & 0.6542 & 0.6386 & 0.6915 & 0.6125 \\
\hline$k \times 10^{2}$ & 1.335 & 1.346 & 1.072 & 1.498 \\
\hline$D \times 10^{5}$ & 6.500 & 7.684 & 8.103 & 4.762 \\
\hline \multirow[t]{2}{*}{$\left(K_{s r} \times 10^{3}\right)$} & 2.512 & 2.115 & 2.330 & 1.194 \\
\hline & \multicolumn{4}{|c|}{ Water- $60 \%$ of THF } \\
\hline$S_{e q}$ & 1.680 & 1.766 & 2.174 & 2.323 \\
\hline EWLC & 0.6268 & 0.6385 & 0.6850 & 0.6991 \\
\hline$n$ & 0.5525 & 0.5405 & 0.5281 & 0.5100 \\
\hline$k \times 10^{2}$ & 3.424 & 2.660 & 2.573 & 2.440 \\
\hline$D \times 10^{5}$ & 7.496 & 5.976 & 3.195 & 3.549 \\
\hline$\left(K_{s r} \times 10^{3}\right)$ & 4.743 & 2.766 & 2.078 & 1.306 \\
\hline
\end{tabular}


IPNs and AAm/SVS/ZEO hybrid hydrogels having of $240 \mu \mathrm{L}$ SVS with different CMC and different ZEO contents, when CMC and ZEO have been added to the hydrogel systems. Incorporation of CMC and ZEO into the copolymer network leads to higher values of $S_{e q}$. The reason of this increase may be the polymeric structure and partially hydrophilic character of CMC and ZEO. So, it was seen that increasing of the value of the $S_{\text {eq }}$, because of increasing of hydrophilic character at cross-linked polymeric systems. On the other hand, again it can be seen that similar characteristic behavior on the some swelling, kinetics and diffusion parameters, if Tables 4-6 have been investigated.

\subsection{Effect of Solvent on Swelling and Diffusion}

Swelling of AAm/SVS hydrogels, AAm/SVS/CMC semi IPNs, AAm/SVS/ZEO hybrid hydrogels, and AAm/SVS/CMC/ZEO biohybrid hydrogel may be evaluated by the composition of solvent. Variations of the swelling factor $(S)$ of the hydrogels as a function of the solvent contents/concentration in the binary mixtures of water-solvent have been plotted in Figures 13-16. The values of some swelling and diffusion parameters of AAm/SVS hydrogels, AAm/SVS/CMC semi IPNs, AAm/SVS/ZEO hybrid hydrogels, and AAm/SVS/CMC/ZEO biohybrid hydrogel systems in water or binary mixture of water-solvent (ACE, MET and THF) were tabulated in Tables 9-12.

In Tables 9-12, the values of $S_{e q}$ of the hydrogels in binary mixture of water-solvent (ACE, MET and THF) are lower than the value of the hydrogels swollen in water. MET has got one alkyl group, but ACE and THF have got more than alkyl group from MET. With the increasing of alkyl group in the solvent, water diffusion can be affected by the depending on organic molecular structure and pores of AAm/SVS hydrogels, AAm/SVS/CMC semi IPNs, AAm/SVS/ZEO hybrid hydrogels, and AAm/SVS/CMC/ZEO biohybrid hydrogels.

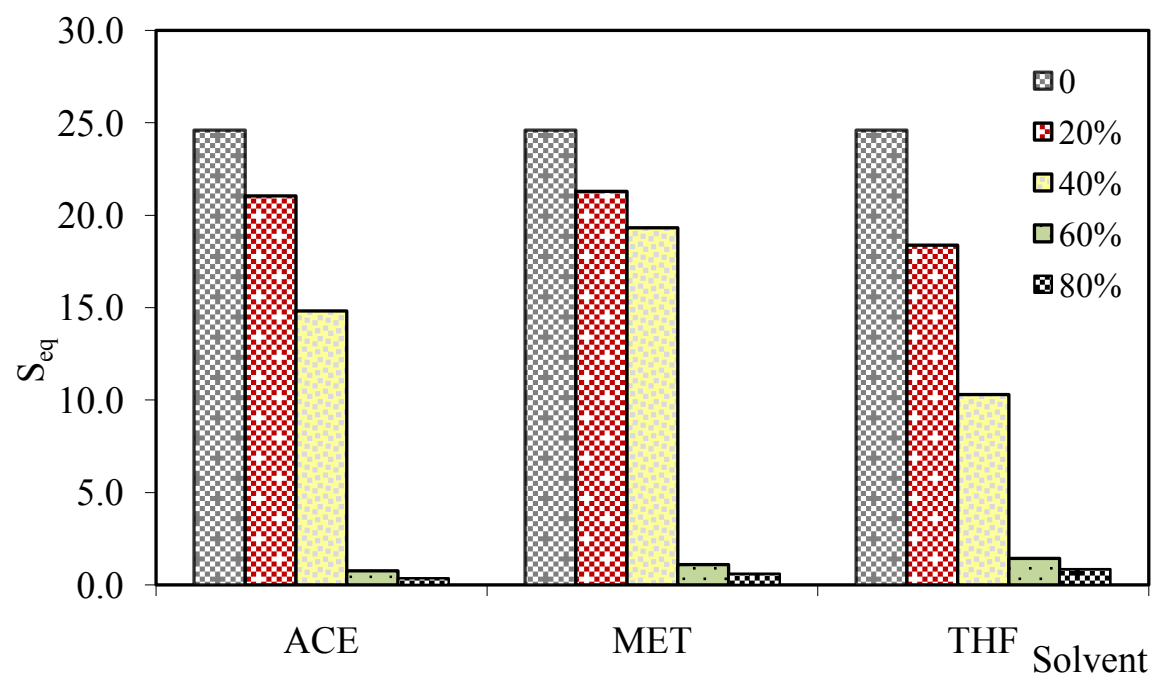

Figure 13. Variation of the equilibrium swelling factor $\left(S_{e q}\right)$ of AAm/SVS hydrogels as a function of the solvent composition in the binary mixtures of water-solvent. 


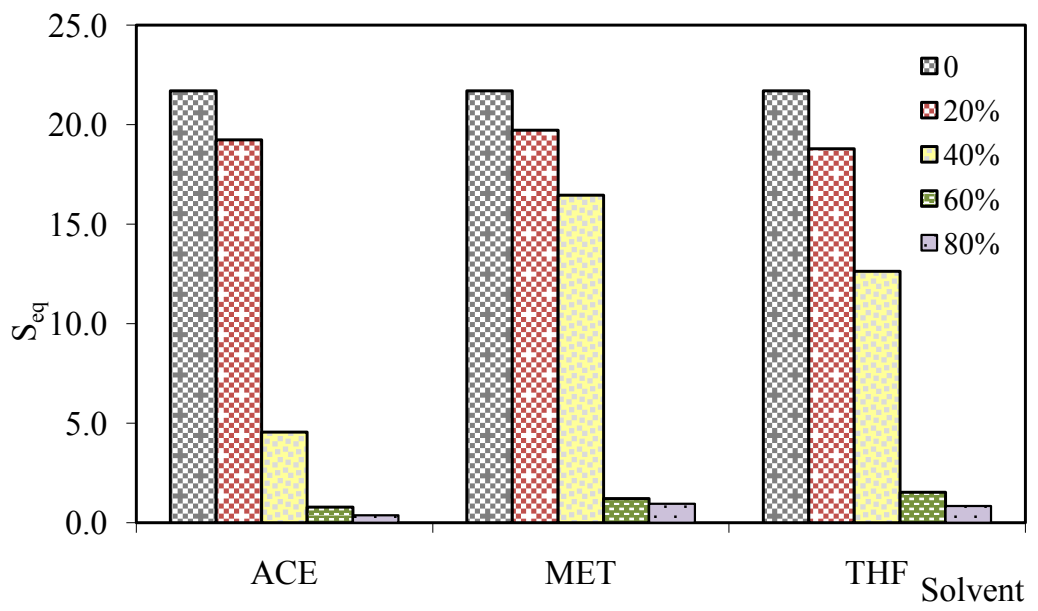

Figure 14. Variation of the equilibrium swelling factor $\left(S_{e q}\right)$ of AAm/SVS/ZEO hybrid hydrogels as a function of the solvent composition in the binary mixtures of water-solvent.

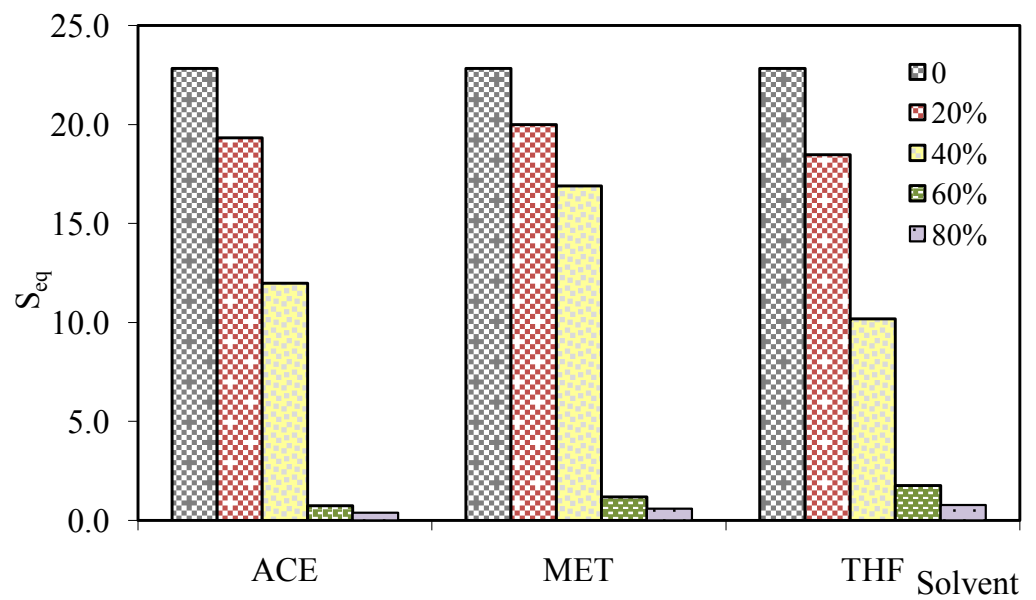

Figure 15. Variation of the equilibrium swelling factor $\left(S_{e q}\right)$ of AAm/SVS/CMC semi IPN hydrogels as a function of the solvent composition in the binary mixtures of water-solvent.

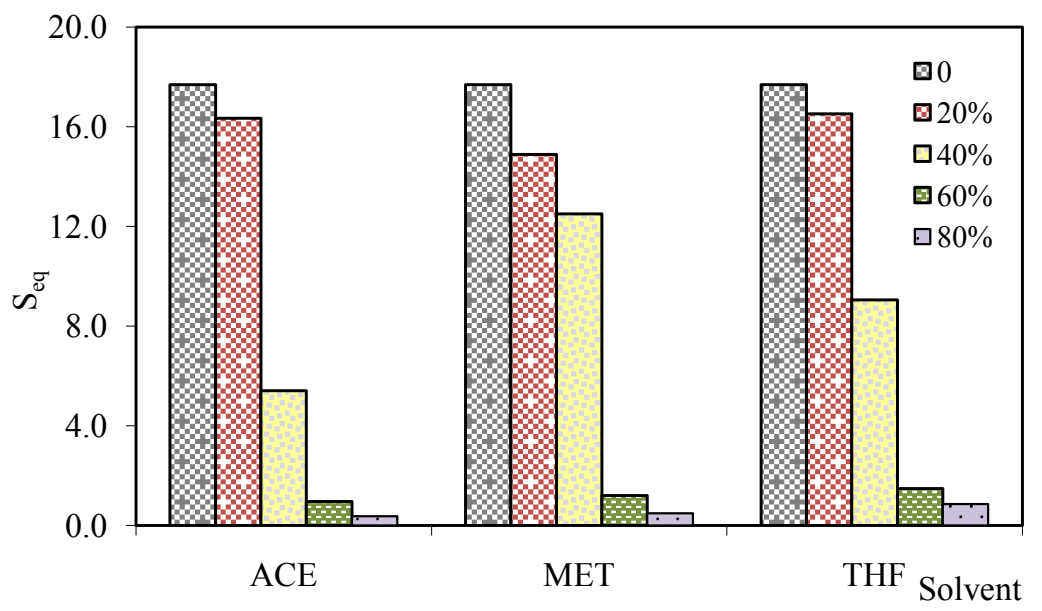

Figure 16. Variation of the equilibrium swelling factor $\left(S_{\text {eq }}\right)$ of AAm/SVS/CMC/ZEO biohybrid hydrogels as a function of the solvent composition in the binary mixtures of water-solvent. 
Table 9. The values of some swelling and diffusion parameters of AAm/SVS hydrogels in water or binary mixture of water-solvent (ACE, MET and THF).

\begin{tabular}{|c|c|c|c|c|c|}
\hline Percentage of solvent. & water & $20 \%$ & $40 \%$ & $60 \%$ & $80 \%$ \\
\hline & & & $\mathrm{ACE}$ & & \\
\hline$S_{e q}$ & 24.607 & 21.038 & 14.039 & 0.771 & 0.378 \\
\hline EWLC & 0.9609 & 0.9546 & 0.9335 & 0.4352 & 0.2744 \\
\hline$n$ & 0.7270 & 0.8210 & 0.9146 & 0.5884 & 0.6775 \\
\hline$k \times 10^{2}$ & 1.117 & 0.555 & 0.162 & 2.780 & 0.831 \\
\hline$D \times 10^{5}$ & 68.065 & 70.185 & 29.270 & 9.726 & 3.391 \\
\hline \multirow[t]{2}{*}{$\left(K_{s r} \times 10^{3}\right)$} & 3.541 & 2.952 & 1.209 & 4.432 & 1.851 \\
\hline & & & MET & & \\
\hline$S_{e q}$ & 24.607 & 21.289 & 19.325 & 1.112 & 0.613 \\
\hline EWLC & 0.9609 & 0.9551 & 0.9508 & 0.5266 & 0.3802 \\
\hline$n$ & 0.7270 & 0.7768 & 0.8706 & 0.6564 & 0.8081 \\
\hline$k \times 10^{2}$ & 1.117 & 0.436 & 0.152 & 1.416 & 0.024 \\
\hline$D \times 10^{5}$ & 68.065 & 21.661 & 21.047 & 9.955 & 0.136 \\
\hline \multirow[t]{2}{*}{$\left(K_{s r} \times 10^{3}\right)$} & 3.541 & 1.599 & 0.911 & 2.583 & 0.077 \\
\hline & & & THF & & \\
\hline$S_{e q}$ & 24.607 & 18.398 & 10.306 & 1.443 & 0.860 \\
\hline EWLC & 0.9609 & 0.9484 & 0.9116 & 0.5907 & 0.4623 \\
\hline$n$ & 0.7270 & 0.7872 & 0.7310 & 0.5569 & 0.5683 \\
\hline$k \times 10^{2}$ & 1.117 & 0.552 & 0.447 & 3.653 & 2.832 \\
\hline$D \times 10^{5}$ & 68.065 & 4.999 & 12.964 & 14.477 & 5.791 \\
\hline$\left(K_{s r} \times 10^{3}\right)$ & 3.541 & 2.559 & 1.219 & 5.361 & 4.096 \\
\hline
\end{tabular}

Table 10. The values of some swelling and diffusion parameters of AAm/SVS/ZEO biohybride hydrogels in water or binary mixture of water-solvent (ACE, MET and THF).

\begin{tabular}{cccccc}
\hline Percentage of solvent. & water & $20 \%$ & $40 \%$ & $60 \%$ & $80 \%$ \\
\hline$S_{e q}$ & 21.690 & 19.227 & 4.550 & 0.782 & 0.369 \\
EWLC & 0.9559 & 0.9506 & 0.8198 & 0.4387 & 0.2697 \\
$n$ & 0.7280 & 0.8436 & 0.7663 & 0.5992 & 1.0628 \\
$k \times 10^{2}$ & 1.215 & 0.528 & 1.052 & 2.500 & 0.081 \\
$D \times 10^{5}$ & 83.868 & 80.339 & 35.530 & 10.276 & 10.344 \\
$\left(K_{s r} \times 10^{3}\right)$ & 4.061 & 3.205 & 4.734 & 4.082 & 1.657 \\
& & & MET & & \\
$S_{e q}$ & 21.690 & 19.713 & 16.465 & 1.093 & 0.950 \\
$\mathrm{EWLC}$ & 0.9559 & 0.9517 & 0.9427 & 0.5222 & 0.4873 \\
$n$ & 0.7280 & 0.7809 & 0.7896 & 0.6095 & 0.6269 \\
$k \times 10^{2}$ & 1.215 & 0.486 & 0.251 & 1.712 & 0.065 \\
$D \times 10^{5}$ & 83.868 & 23.635 & 11.117 & 5.786 & 0.145 \\
$\left(K_{s r} \times 10^{3}\right)$ & 4.061 & 1.946 & 0.922 & 2.319 & 0.066 \\
\hline
\end{tabular}




\section{Continued}

\begin{tabular}{cccccc}
\hline$S_{e q}$ & 21.690 & 18.784 & 12.648 & 1.536 & 0.855 \\
EWLC & 0.9559 & 0.9495 & 0.9267 & 0.6057 & 0.4610 \\
$n$ & 0.7280 & 0.7731 & 0.7744 & 0.5746 & 0.5927 \\
$k \times 10^{2}$ & 1.215 & 0.572 & 0.321 & 2.719 & 3.420 \\
$D \times 10^{5}$ & 83.868 & 36.581 & 14.591 & 11.033 & 16.546 \\
$\left(K_{s r} \times 10^{3}\right)$ & 4.061 & 2.201 & 1.127 & 3.786 & 6.822
\end{tabular}

Table 11. The values of some swelling and diffusion parameters of AAm/SVS/CMC semi IPN hydrogels in water or binary mixture of water-solvent (ACE, MET and THF).

\begin{tabular}{|c|c|c|c|c|c|}
\hline Percentage of solvent. & water & $20 \%$ & $40 \%$ & $60 \%$ & $80 \%$ \\
\hline & & & $\mathrm{ACE}$ & & \\
\hline$S_{e q}$ & 22.833 & 19.325 & 11.972 & 0.748 & 0.397 \\
\hline EWLC & 0.9580 & 0.9508 & 0.9229 & 0.4279 & 0.2840 \\
\hline $\mathrm{n}$ & 0.6908 & 0.8076 & 0.8331 & 0.5698 & 0.8571 \\
\hline$k \times 10^{2}$ & 0.932 & 0.493 & 0.440 & 2.953 & 0.369 \\
\hline $\mathrm{D} \times 10^{5}$ & 40.954 & 47.611 & 31.159 & 7.634 & 9.519 \\
\hline \multirow[t]{2}{*}{$\left(\mathrm{K}_{\mathrm{sr}} \times 10^{3}\right)$} & 2.051 & 2.323 & 2.489 & 4.161 & 1.790 \\
\hline & & & MET & & \\
\hline$S_{e q}$ & 22.833 & 19.995 & 16.910 & 1.196 & 0.595 \\
\hline EWLC & 0.9580 & 0.9524 & 0.9442 & 0.5447 & 0.3731 \\
\hline$n$ & 0.6908 & 0.7602 & 0.7966 & 0.6386 & 0.8344 \\
\hline$k \times 10^{2}$ & 0.932 & 0.454 & 0.230 & 1.346 & 0.017 \\
\hline$D \times 10^{5}$ & 40.954 & 26.343 & 12.763 & 7.684 & 0.205 \\
\hline \multirow[t]{2}{*}{$\left(K_{s r} \times 10^{3}\right)$} & 2.051 & 1.540 & 0.869 & 2.115 & 0.829 \\
\hline & & & THF & & \\
\hline$S_{e q}$ & 22.833 & 18.469 & 10.178 & 1.766 & 0.774 \\
\hline EWLC & 0.9580 & 0.9486 & 0.9105 & 0.6385 & 0.4362 \\
\hline$n$ & 0.6908 & 0.7684 & 0.7249 & 0.5405 & 0.5548 \\
\hline$k \times 10^{2}$ & 0.932 & 0.503 & 0.434 & 2.660 & 3.308 \\
\hline$D \times 10^{5}$ & 40.954 & 30.617 & 10.020 & 5.976 & 8.000 \\
\hline$\left(K_{s r} \times 10^{3}\right)$ & 2.051 & 1.792 & 1.094 & 2.766 & 4.158 \\
\hline
\end{tabular}

Table 12. The values of some swelling and diffusion parameters of AAm/SVS/CMC/ZEO biohybride hydrogels in water or binary mixture of water-solvent (ACE, MET and THF).

\begin{tabular}{crrrrr}
\hline Percentage of solvent. & water & $20 \%$ & $40 \%$ & $60 \%$ & $80 \%$ \\
\hline$S_{e q}$ & 17.681 & 16.339 & ACE & & \\
\hline
\end{tabular}




\section{Continued}

\begin{tabular}{|c|c|c|c|c|c|}
\hline EWLC & 0.9465 & 0.9423 & 0.8439 & 0.4908 & 0.2708 \\
\hline$n$ & 0.7573 & 0.8068 & 0.7321 & 0.6226 & 1.0191 \\
\hline$k \times 10^{2}$ & 1.578 & 0.580 & 0.820 & 1.919 & 0.128 \\
\hline$D \times 10^{5}$ & 178.433 & 51.954 & 21.354 & 7.998 & 12.919 \\
\hline \multirow[t]{2}{*}{$\left(K_{s r} \times 10^{3}\right)$} & 7.039 & 2.792 & 2.718 & 3.235 & 1.877 \\
\hline & & & MET & & \\
\hline$S_{e q}$ & 17.681 & 14.899 & 12.504 & 1.209 & 0.499 \\
\hline EWLC & 0.9465 & 0.9371 & 0.9259 & 0.5472 & 0.3292 \\
\hline$n$ & 0.7573 & 0.7472 & 0.8162 & 0.6579 & 0.5071 \\
\hline$k \times 10^{2}$ & 1.578 & 0.603 & 0.256 & 1.110 & 0.223 \\
\hline$D \times 10^{5}$ & 178.433 & 26.443 & 21.265 & 7.592 & 0.015 \\
\hline \multirow[t]{2}{*}{$\left(K_{s r} \times 10^{3}\right)$} & 7.039 & 2.003 & 1.157 & 1.985 & 0.140 \\
\hline & & & THF & & \\
\hline$S_{e q}$ & 17.681 & 16.522 & 9.045 & 1.483 & 0.855 \\
\hline EWLC & 0.9465 & 0.9429 & 0.9005 & 0.5973 & 0.4610 \\
\hline$n$ & 0.7573 & 0.7448 & 0.7105 & 0.5164 & 0.5668 \\
\hline$k \times 10^{2}$ & 1.578 & 0.657 & 0.522 & 3.694 & 3.229 \\
\hline$D \times 10^{5}$ & 178.433 & 33.016 & 14.030 & 7.487 & 7.392 \\
\hline$\left(K_{s r} \times 10^{3}\right)$ & 7.039 & 2.086 & 1.256 & 3.853 & 4.877 \\
\hline
\end{tabular}

It was seen that decreasing of the value of $S_{e q}$ of the hydrogels with the increasing composition of the solvents. Here, an important reason, the hydrophobic character of the alkyl groups in the molecular structure. The hydrophobic character can be increased with the increasing of alkyl group of the organic molecular structure. For this reason, the more hydrophobic groups in the solvents get the less the swelling of the hydrogels in binary mixtures of water-solvent (in ACE, in MET and in THF). Again Tables 9-12 show that the values of $S_{e q}$ for binary mixtures of water-20\%; $40 \%$; $60 \%$; and $80 \%$ of ACE are 0.372 - 21.038, for binary mixtures of water-20\%; $40 \%$; $60 \%$; and $80 \%$ of MET are $0.499-21.289$, and for binary mixtures of water- $20 \% ; 40 \% ; 60 \%$; and $80 \%$ of THF are $0.744-18.784$.

For the swelling of AAm/SVS hydrogels, AAm/SVS/CMC semi IPNs, AAm/ SVS/ZEO hybrid hydrogels, and AAm/SVS/CMC/ZEO biohybrid hydrogels in binary mixtures of water-solvent (in ACE, in MET and in THF), it can be expected different behavior in water. This difference can be explained by the dependence of the ionization of the charged groups of the hydrogels in various compositions of binary mixtures of water-solvent. Because of the lower polarisability, high hydrophobicity, and the lower hydrogen bonding occurring in swelling, the swelling value of the hydrogels can be lower than the swelling in water. Also for good description of content of SVS on swelling characterization, col- 
umn plots of $S_{e q}$ versus various contents of SVS for AAm/SVS hydrogels, AAm/ SVS/CMC semi IPNs, AAm/SVS/ZEO hybrid hydrogels, and AAm/SVS/CMC/ ZEO biohybrid hydrogels including of various contents of SVS could have been discussed here again (Figures 6-9). It was seen that the values of $S_{e q}$ of the hydrogels increased with the SVS content in the crosslinked copolymers, again.

\section{Conclusion}

The present work has given the quantitative information on the swelling characteristic of AAm/SVS hydrogels, AAm/SVS/CMC semi IPNs, AAm/SVS/ZEO hybrid hydrogels, and AAm/SVS/CMC/ZEO biohybrid hydrogels in water and in binary mixtures of water-solvent (in ACE, in MET and in THF). Generally, it was seen that swelling of AAm/SVS hydrogels, AAm/SVS/CMC semi IPNs, AAm/SVS/ZEO hybrid hydrogels, and AAm/SVS/CMC/ZEO biohybrid hydrogel increased with the increasing of content of SVS. The hydrogels showed high water absorbency. The value of the equilibrium swelling factor of the hydrogels was 6.614 - 31.997 for water, 0.733 - 0.989 for water- $60 \%$ of acetone, 0.872 1.509 for water- $60 \%$ of methanol, $1.288-2.215$ for water- $60 \%$ of tetrahydrofuran. Here it was seen that there is no swelling in 100\% composition of the solvents such as ACE, MET and THF. The values of $S_{e q}$ of the hydrogels in water are higher than values of $S_{e q}$ of the hydrogels in organic solvents. It can be said that the more hydrophobic groups in binary mixtures of water-solvent get the less the swelling of the hydrogels. The main effect may be the non-hydrophilic character of alkyl groups in molecular structure of ACE, MET and THF. At the end of this study, it is seen that chemically crosslinked AAm/SVS hydrogels, AAm/SVS/CMC semi IPNs, AAm/SVS/ZEO hybrid hydrogels, and AAm/SVS/ $\mathrm{CMC} / \mathrm{ZEO}$ biohybrid hydrogels may be used as a sorbent in binary mixtures of water-solvent such as ACE, or MET, or THF. The utilization of these types of hydrogels in pharmaceuticals, agriculture, biotechnology, environment, sorption, separation, purification, water treatment process and other related area makes hydrogel more popular.

\section{Acknowledgements}

The work was supported by Adnan Menderes University Research Fund, under project number FEF 15038.

\section{Conflicts of Interest}

The authors declare no conflicts of interest regarding the publication of this paper.

\section{References}

[1] Jaspal, D. and Malviya, A. (2020) Composites for Wastewater Purification: A Review. Chemosphere, 246, Article ID: 125788. https://doi.org/10.1016/j.chemosphere.2019.125788 
[2] Nasir, A., Kausar, A. and Younus, A. (2015) A Review on Preparation, Properties and Applications of Polymeric Nanoparticle-Based Materials. Polymer-Plastics Technology and Engineering, 54, 325-341. https://doi.org/10.1080/03602559.2014.958780

[3] Mousa, M.H., Dong, Y. and Davies, I.J. (2016) Recent Advances in Bionanocomposites: Preparation, Properties, and Applications. International Journal of Polymeric Materials and Polymeric Biomaterials, 65, 225-254. https://doi.org/10.1080/00914037.2015.1103240

[4] Sanchez, L.M., Ollier, R.P. and Alvarez, V.A. (2019) Sorption Behavior of Polyvinyl Alcohol/Bentonite Hydrogels for Dyes Removal. Journal of Polymer Research, 26, Article No. 142. https://doi.org/10.1007/s10965-019-1807-4

[5] Karadağ, E., Öztürk, Z.D.K., Üzüm, Ö.B. and Kundakc1, S. (2019) Swelling Performance Studies of Acrylamide/Potassium 3-Sulfopropyl Methacrylate/Sodium Alginate/Bentonite Biohybrid Sorbent Hydrogels in Binary Mixtures of Water-Solvent. Journal of Encapsulation and Adsorption Sciences, 9, 35-61. https://doi.org/10.4236/jeas.2019.91003

[6] Haider, S., Kausar, A. and Muhammad, B. (2017) Overview on Polystyrene/Nanoclay Composite: Physical Properties and Application. Polymer-Plastics Technology and Engineering, 56, 917-931. https://doi.org/10.1080/03602559.2016.1233563

[7] Teixeira, R.S.P., Correa, R.J., Bello Forero, J.S., Silva, M.G.S., Oliveira, R.C.S. and Souza, R.S. (2017) Comparative Study of PEO and PVA Hydrogels for Removal of Methylene Blue Dye from Wastewater. Journal of Applied Polymer Science, 134, Article No. 45043. https://doi.org/10.1002/app.45043

[8] Aydınoğlu, D., Akgül, Ö., Bayram, V. and Şen, S. (2014) Polymer Nanocomposite Hydrogels with Improved Metal Adsorption Capacity and Swelling Behavior: Influence of Spirulina Immobilization onto Montmorillonite Clay. Polymer-Plastics Technology and Engineering, 53, 1706-1722. https://doi.org/10.1080/03602559.2014.919656

[9] Zhu, L., Zhang, L., Tang, Y. and Kou, X. (2014) Synthesis of Sodium Alginate Graft Poly(Acrylic Acid-Co-2-Acrylamido-2-Methyl-1-Propane Sulfonic Acid)/Attapulgite Hydrogel Composite and the Study of Its Adsorption. Polymer-Plastics Technology and Engineering, 53, 74-79. https://doi.org/10.1080/03602559.2013.843691

[10] Karadağ, E., Üzüm, Ö.B. and Kundakc1, S. (2009) Water Sorption and Dye Uptake Studies of Highly Swollen AAm/AMPS Hydrogels and Semi-IPN's with PEG. Polymer-Plastics Technology and Engineering, 48, 1217-1229. https://doi.org/10.1080/03602550903159044

[11] Chandrika, K.S.V.P., Singh, A., Rathore, A. and Kumar, A. (2016) Novel Crosslinked Guar Gum-g-Poly(Acrylate) Porous Superabsorbent Hydrogels: Characterization and Swelling Behavior in Different Environments. Carbohydrate Polymer, 149, 175-185. https://doi.org/10.1016/j.carbpol.2016.04.077

[12] Tamura, T., Kawabata, N. and Satoh, M. (2000) Swelling Behavior of Poly( $\alpha$-Hydroxy Acrylic Acid) Gel in Water/Organic Solvent Mixtures. Polymer Bulletin, 44, 209-214. https://doi.org/10.1007/s002890050594

[13] Ulbricht, M. (2006) Advanced Functional Polymer Membranes. Polymer, 47, 2217 2262. https://doi.org/10.1016/j.polymer.2006.01.084

[14] Çaykara, T. and Doğmuş, M. (2004) The Effect of Solvent Composition on Swelling and Shrinking Properties of Poly(Acrylamide-Co-Itaconic Acid) Hydrogels. European Polymer Journal, 40, 2605-2609. https://doi.org/10.1016/j.eurpolymj.2004.06.024 
[15] Üzüm, Ö.B. and Karadağ, E. (2010) Equilibrium Swelling Studies of Chemically Crosslinked Highly Swollen Acrylamide-Sodium Acrylate Hydrogels in Various Water-Solvent Mixtures. Polymer-Plastics Technology and Engineering, 49, 609-616. https://doi.org/10.1080/03602551003664537

[16] Kabiri, K., Zohuriaan-Mehr, M.J., Mirzadeh, H. and Kheirabadi, M. (2010) Solvent-, Ion- and pH-Specific Swelling of Poly(2-Acrylamido-2-Methylpropane Sulfonic Acid) Superabsorbing Gels. Journal of Polymer Research, 17, 203-212. https://doi.org/10.1007/s10965-009-9306-7

[17] Hüther, A., Xu, X. and Maurer, G. (2004) Swelling of n-Isopropyl Acrylamide Hydrogels in Water and Aqueous Solutions of Ethanol and Acetone. Fluid Phase Equilibria, 219, 231-244. https://doi.org/10.1016/j.fluid.2003.08.002

[18] Ilavsky, M., Mamytbekov, G., Hanykova, L. and Dusek, K. (2002) Phase Transition in Swollen Gels 31. Swelling and Mechanical Behaviour of Interpenetrating Networks Composed of Poly(1-Vinyl-2-Pyrrolidone) and Polyacrylamide in Water/Acetone Mixtures. European Polymer Journal, 38, 875-883. https://doi.org/10.1016/S0014-3057(01)00254-3

[19] Orlov, Y., Xu, X. and Maurer, G. (2005) Swelling of a N-Isopropyl Acrylamide Hydrogels in Two Aqueous/Organic Two-Phase Systems. Fluid Phase Equilibria, 235, 18-25. https://doi.org/10.1016/j.fluid.2005.05.025

[20] Karadağ, E., Yel, B., Kundakcı, S. and Üzüm, Ö.B. (2017) Synthesis and Application of Acrylamide/Sodium Vinylsulfonate/Carboxymethyl Cellulose/Zeolite Hybrid Hydrogels as Highly Swollen Effective Adsorbents for Model Cationic Dye Removal. Desalination and Water Treatment, 74, 402-414. https://doi.org/10.5004/dwt.2017.20613

[21] Karadağ, E. and Kundakçı, S. (2015) Application of Highly Swollen Novel Biosorbent Hydrogels in Uptake of Uranyl Ions from Aqueous Solutions. Fibers and Polymers, 16, 2165-2176. https://doi.org/10.1007/s12221-015-5522-4

[22] Karadağ, E., Nalbantoğlu, A., Kundakcı, S. and Üzüm, Ö.B. (2014) Highly Swollen Polymer/Clay Composite Sorbent-Based AAm/AMPS Hydrogels and Semi-IPNs Composed of Carboxymethyl Cellulose and Montmorillonite and Cross-Linked by PEGDA. Polymer-Plastics Technology and Engineering, 53, 54-64. https://doi.org/10.1080/03602559.2013.843689

[23] Karadağ, E. and Kundakçı, S. (2014) Preliminary Swelling and Dye Sorption Studies of Acrylamide/4-Styrenesulfonic Acid Sodium Salt Copolymers and Semi-Interpenetrating Polymer Networks Composed of Gelatin and/or PEG. Polymer Bulletin, 71, 351-370. https://doi.org/10.1007/s00289-013-1065-2

[24] Karadağ, E., Topaç, F., Kundakcı, S. and Üzüm, Ö.B. (2014) Novel Composite Sorbent AAm/MA Hydrogels Containing Starch and Kaolin for Water Sorption and Dye Uptake. Bulletin of Materials Science, 37, 1637-1646. https://doi.org/10.1007/s12034-014-0723-9

[25] Lee, S.J., Kim, S.S. and Lee, Y.M. (2000) Interpenetrating Polymer Network Hydrogels Based on Poly(Ethylene Glycol) Macromer and Chitosan. Carbohydrate Polymer, 41, 197-205. https://doi.org/10.1016/S0144-8617(99)00088-0

[26] Kim, S.J., Park, S.J. and Kim, S.I. (2003) Synthesis and Characterization of Interpenetrating Polymer Network Hydrogels Composed of Poly(Vinyl Alcohol) and Poly(N-Isopropylacrylamide). Reactive and Functional Polymers, 55, 61-67. https://doi.org/10.1016/S1381-5148(02)00215-8

[27] Saraydin, D., Karadağ, E., Işıkver, Y., Şahiner, N. and Güven, O. (2004) The Influence of Preparation Methods on the Swelling and Network Properties of Acryla- 
mide Hydrogels with Crosslinkers. Journal of Macromolecular Science Part A Pure and Applied Chemistry, 41, 421-433. https://doi.org/10.1081/MA-120028476

[28] Peppas, N.A. and Franson, N.M. (1983) The Swelling Interface Number as a Criterion for Prediction of Diffusional Solute Release Mechanisms in Swellable Polymers. Journal of Polymer Science, 21, 983-997. https://doi.org/10.1002/pol.1983.180210614

[29] Am Ende, M.T. and Peppas, N.A. (1997) Transport of Ionizable Drugs and Proteins in Crosslinked Poly(Acrylic Acid) and Poly(Acrylic Acid-Co-2-Hydroxyethyl Methacrylate) Hydrogels. II. Diffusion and Release Studies. Journal of Controlled Release, 48, 47-56. https://doi.org/10.1016/S0168-3659(97)00032-1

[30] Dengre, R., Bajpai, M. and Bajpai, S.K. (2000) Release of Vitamin B12 from Poly(N-Vinyl-2-Pyrrolidione)-Crosslinked Polyacrylamide Hydrogels. Journal of Applied Polymer Science, 76, 1706-1714.

https://doi.org/10.1002/(SICI)1097-4628(20000613)76:11<1706::AID-APP12>3.0.C O;2-W

[31] Çaykara, T., Kiper, S. and Demirel, G. (2006) Thermosensitive Poly(N-Isopropylacrylamide-Co-Acrylamide) Hydrogels: Synthesis, Swelling and Interaction with Ionic Surfactants. European Polymer Journal, 42, 348-355.

https://doi.org/10.1016/j.eurpolymj.2005.07.006

[32] Ali, A.E., Shawky, H.A., Abd El Rehim, H.A. and Hegazy, H.A. (2003) Synthesis and Characterization of PVP/AAc Copolymer Hydrogel and Its Applications in the Removal of Heavy Metals from Aqueous Solution. European Polymer Journal, 39, 2337-2344. https://doi.org/10.1016/S0014-3057(03)00150-2 